\title{
Conditional inactivation of the murine serum response factor in the pancreas leads to severe pancreatitis
}

\author{
Francisco Miralles ${ }^{1}$, Sophie Hebrard ${ }^{1}$, Luciane Lamotte $^{1}$, Beatrice Durel ${ }^{1}$, \\ Helene Gilgenkrantz ${ }^{1}$, Zhenlin $\mathrm{Li}^{2}$, Dominique Daegelen ${ }^{1}$, David Tuil ${ }^{1}$ and Rajiv L Joshi ${ }^{1}$ \\ ${ }^{1}$ Departement de Génétique et Développement, Institut Cochin, INSERM U567, CNRS UMR8104, Université \\ René Descartes Paris V, Paris, France and ${ }^{2}$ CNRS UMR7079, Université Pierre et Marie Curie Paris VII, Paris, \\ France
}

\begin{abstract}
The Serum Response Factor (SRF) is widely expressed transcription factor acting at the confluence of multiple signaling pathways and has been implicated in the control of differentiation, growth, and cell death. In the present study, we found that SRF is expressed in the developing and adult pancreas. To explore the possible role of SRF in this organ, we have generated mutant mice with conditional disruption of the Srf gene. Such mutants presented normal development of both the exocrine and endocrine pancreas indicating that SRF is dispensable for pancreas ontogenesis. However, after weaning, these mice developed profound morphological alterations of the exocrine pancreas, which were reminiscent of severe pancreatitis. In these mice, massive acinar injury, Nuclear Factor Kappa B activation and proinflammatory cytokines release led to complete destruction of the exocrine pancreas and its replacement by adipose tissue. Despite these changes, the organization and function of the endocrine islets of Langerhans remained well-preserved. This new animal model of spontaneous pancreatitis could prove a valuable tool to gain further insight into the physiopathology of this disease.
\end{abstract}

Laboratory Investigation (2006) 86, 1020-1036. doi:10.1038/labinvest.3700457; published online 7 August 2006

Keywords: acinar cells; pancreatitis; SRF; transgenic animals

The Serum Response Factor (SRF) is a widely expressed transcription factor. SRF is a member of the MADS box family with a DNA-binding and dimerization domain, which binds the sequence CC(A/T)6GG known as the CArG box. ${ }^{1}$ This sequence has been identified in the promoter regions of different genes including many immediate early genes such as $C$-fos, fos-B, jun-B, Egr1, neuronal genes, such as Nurr1, Nurr2 and muscle genes such as skeletal $\alpha$-actin, $\alpha$-myosin heavy chain, tropomyosin, Atrial natriuretic factor $(A N F)$, Sarcoplasmic Reticulum $\mathrm{Ca}^{2+}$-ATPase (SERCA2). ${ }^{2}$ SRF regulates the activity of the CArG box dependent genes through two different mechanisms: the ternary complex factors (TCFs)-dependent mechanism involves the phosphorylation by the MAPKs of the TCFs. SRF binds to phosphorylated-TCFs and

Correspondence: Dr F Miralles, PhD, Department de Génétique et Développement, Institut Cochin, 24, rue du Faubourg Saint-Jacques, 75014 Paris, France.

E-mail: miralles@cochin.inserm.fr

Received 28 March 2006; revised and accepted 22 June 2006; published online 7 August 2006 recruits them to ETS-binding sites adjacent to CArG boxes. ${ }^{3} \mathrm{SRF}$ also regulates gene expression through a TCF-independent mechanism involving the Rho family of GTPases. ${ }^{4}$ The Srf gene itself could be regulated through GTPase RhoA-dependent pathways. $^{2}$

A number of studies have implicated SRF in cell growth, differentiation, and death in mammals. ${ }^{2,5}$ Mice null for the $\operatorname{Srf}$ gene develop normally until embryonic day 6.5 (E6.5), but the mesodermal germ layer does not form and as a result the embryos die between E8.5 and E12.5. ${ }^{6}$ Overexpression of a dominant negative form of SRF damages embryogenesis. ${ }^{7}$ Consistent with its role in the regulation of muscle-specific genes, SRF is strongly expressed in embryonic heart as well as in skeletal, and smooth muscle tissues. Overexpression of SRF in the heart leads to hypertrophic cardiomyopathy and heart failure in transgenic mice. ${ }^{7}$ The targeted inactivation of the $S r f$ gene in the developing heart results in myocardial defects leading to embryonic lethality. ${ }^{8,9}$ Recently, SRF has been identified as a transcriptional regulator of the expression of the antiapoptotic genes Bcl-2, Bcl-xl, and Mcl-1., ${ }^{5,10}$ Thus, SRF 
could be involved in the control of programmed cell death.

Several genes containing CArG boxes in their promoter regions are expressed in the pancreas, namely the early expression genes $c$-fos, Egr-1, jun$B$, cytoskeletal genes such as $\beta$-actin and vinculin, the transcription factor GATA-4, the $\mathrm{Na}^{+} / \mathrm{Ca}^{2+}$ exchanger NCX, and the CFTR and SERCA2 genes. All these genes have been implicated in the development or function of either the endocrine or exocrine cells of the pancreas. ${ }^{11-16}$ In the current study, we first observed that SRF is expressed throughout the developing and adult pancreas. Although in the adult organ SRF is expressed by all the pancreatic cell types, its level of expression appears to be higher in the islet cells.

To study the role of SRF in the control of pancreas development and/or function suggested by all these observations, we have conditionally inactivated the Srf gene in the mouse pancreas by using a Cre/LoxP system. This was achieved by crossing mutant mice carrying a floxed Srf allele ${ }^{9}$ with $p P d \times 1$-Cre transgenic mice. ${ }^{17}$ The $p P d x 1-C r e$ mice express the recombinase Cre under the control of the promoter of the $P d x 1$ (Pancreatic and duodenal homeobox 1) gene. ${ }^{18}$ We have thus generated mutant mice with specific inactivation of the $\operatorname{Srf}$ gene in the entire pancreas. The characterization of these mice revealed a normal pancreas at birth indicating that SRF is dispensable for pancreatic development. In addition, these mice did not develop any alterations in the $\beta$-cell mass or function and remained capable of maintaining normal glucose homeostasis. However, most animals developed a severe pancreatitis after weaning, leading to the total destruction of the exocrine pancreas. In the older animals, the exocrine tissue was completely replaced by adipose tissue, without affecting the structure and function of the endocrine pancreas. This phenotype is discussed in light of known SRF-target genes, which have been implicated in the development of pancreatitis in animal models or humans.

\section{Materials and methods}

\section{Targeted Inactivation of the Srf Gene in the Pancreas}

To conditionally inactivate the $S r f$ gene in the pancreas, $S r f^{F / F}$ mice (C57BL/6 background) were bred with $p P d x 1-C r e$ mice (ICR/CD-1 background, kindly provided by D Melton) giving double transgenic $p P d \times 1-C r e / S r f^{F /+}$ mice. Further crosses between these animals and $S r f^{F / F}$ mice were carried out to obtain $p P d x 1-C r e / S r f^{F / F}$ mice. Genotyping was performed by PCR using tail DNA. Cre-recombinasemediated excision of the floxed Srf allele was analyzed by PCR on DNA prepared from pancreas, as well as from other organs (ie muscle, liver, intestine, duodenum, lung, tail, and heart) and isolated islets of Langerhans. The islets were isolated after collagenase digestion of the pancreas as described..$^{19}$ The primers used to detect the Cre transgene were CreS (5'-CTTCTGTCCGTTTGCCG GTCGTGG-3') and CreR (5'-TTTTGCACGTTCACC GGCATCAACG-3'). Three primers were used for the analysis by PCR of the Srf gene: SF1, SF2 and SF3. SF1 (5'-CTGTAAGGGATGGAAGCAGA-3') and SF2 (5'-TAAGGACAGTGAGGTCCCTA- ${ }^{\prime}$ ) allowed the detection of wild-type (448-bp DNA fragment) and floxed alleles (492-bp DNA fragment). SF1 and SF3 (5'-TTCGGAACTGCCGGGCACTAAA- ${ }^{\prime}$ ) allowed the amplification of a 310-bp DNA fragment when floxed Srf-alleles and PGK-Neo cassette had been recombined by the Cre recombinase. The conditions for PCR were as described. ${ }^{9}$

All transgenic as well as control animals were maintained in a transgenic mouse facility with normal light-dark cycle of $14 \mathrm{~h}$ of light and fed on standard diet ad libitum. All animal manipulations were performed according to the European ethical rules for animal experimentation.

In all experiments control animals used included $S r f^{F / F}$ and wild-type mice.

\section{Histological Analysis}

The pancreas and duodenum from control and $p P d x 1-C r e / S r f^{F / F}$ mice ranging from newborn to 11 months old were carefully dissected, fixed in $4 \%$ paraformaldehyde overnight at $4{ }^{\circ} \mathrm{C}$ and embedded in paraffin. Sections $(5 \mu \mathrm{m})$ were prepared and subjected to trichrome or hematoxylin and eosin staining.

\section{Immunohistochemistry}

Immunohistochemistry was performed on paraffinembedded sections $(5 \mu \mathrm{m})$. On the day of staining, the sections were deparaffined, rehydrated and microwaved to improve antigen-retrieval. Subsequently the sections were permeabilized for $30 \mathrm{~min}$ in $0.1 \%$ Triton X-100 in PBS, and blocking of unspecific reactivity was performed for $1 \mathrm{~h}$ in $3 \%$ BSA in PBS. Primary antibodies were added at the appropriate dilutions in $0.1 \%$ Triton X-100/3\% BSA in PBS and left to react overnight. The excess of antibody was removed and the sections were washed three times for $5 \mathrm{~min}$ in $0.1 \%$ Tween 20PBS. Appropriate horseradish peroxidase HRP-conjugated antibodies were then added and incubated for $1 \mathrm{~h}$. After extensive washing in $0.1 \%$ Tween 20 PBS (five times for $5 \mathrm{~min}$ ), the sections were washed for 5 min in PBS and revealed with diaminobenzidine substrate (Vector). For SRF immunostaining the more sensitive substrate VIP (Vector) was used. Finally the sections were dehydrated, counterstained with hematoxylin-eosin and mounted with Eukitt (Kindler). The sections were examined and photographed using a microscope (Eclipse E800, Nikon) equipped with a digital camera (DXM1200, Nikon) and adapted image acquisition software 
(ACT-1, Nikon). The antibodies used in this study, source and dilution were as follows: rabbit anti-SRF antibody, Santa Cruz, 1:200; mouse anti-Somatostatin, Dako, 1:500; mouse anti-Glucagon, Sigma, 1:2000; mouse anti-Insulin, Sigma, 1:1000; guineapig anti-insulin, Dako, 1:2000; rabbit anti-Pancreatic peptide, Dako, 1:1200; rabbit anti-Amylase, Sigma, 1:2000; rabbit anti-Trypsin, C. Figarella, France, 1:000; rabbit anti-Lipase, C. Figarella, France, 1:000; mouse anti-NF-kB p65 subunit, Chemicon International 1:1000; rabbit anti-activated caspase-3, BD Biosciences, 1:100; mouse anti- $\beta$-catenin, BD Biosciences, 1:200; mouse anti-BrdU, Sigma, 1:200.

\section{Proliferation and Apoptosis}

For in vivo cell proliferation assays, 4-week old control and $p P d \times 1-C r e / S r f^{F / F}$ mice were intraperitoneally injected with BrdU ( $50 \mathrm{mg} / \mathrm{kg}$ body weight). After $6 \mathrm{~h}$, the mice were killed and the pancreas were dissected and fixed as described. Pancreatic sections were immunostained with anti-BrdU antibodies. The proliferation index was calculated by averaging the number of BrdU positive nuclei in 30 fields per pancreas at $\times 200$ magnification. Apoptosis was evaluated by two different methods. Antiactivated caspase-3 immunostaining and by using the transferase-mediated dUTP nick end-labeling (TUNEL) assay (ApopTag, Serologicals Co.) following the manufacturer's protocol. The apoptosis index was determined by counting the amount of activated caspase-3 positive nuclei or TUNEL positive nuclei seen in 10 representative fields per pancreas at $\times 400$ magnification.

\section{Morphometric Analysis}

The $\beta$-cell area and the total area of each section were determined with appropriated image analysis software (Biocom Visiol@b 2000). The relative $\beta$-cell area was calculated by dividing the area of all insulin positive cells in one section by the total area of the section. The $\beta$-cell size was determined on sections stained with anti-insulin antibodies by evaluating the mean cross-sectional area of individual $\beta$-cells. The $\beta$-cell area in islets was measured as described above and the number of $\beta$-cell nuclei in islets was counted.

\section{Metabolic Parameters}

Glycemia and insulinemia were determined in fed animals and after a fasting of $18 \mathrm{~h}$. Blood samples were obtained from the retroorbital sinus using heparinized microcapillars. Glycemia was measured with a glucometer (Bayer Diagnostics). Serum insulinemia was measured by RIA immunoassay (Insulin 125I RIA, ICN). Intraperitoneal glucose tolerance tests (IPGTT) were performed after a fasting of $18 \mathrm{~h}$. The animals received an intraperitoneally injection of glucose $(1.5 \mathrm{~g} / \mathrm{kg}$ of body weight), samples of blood were collected from the retroorbital sinus at different times, and blood glucose levels were determined as above.

\section{Western Blot Analysis}

To analyze circulating amylase and lipase levels, whole blood was isolated from control and $P d \times 1$ $\mathrm{Cre} / \mathrm{Srf} \mathrm{f}^{\mathrm{F} / \mathrm{F}}$ mice. Blood was incubated at room temperature for $2 \mathrm{~h}$, and then centrifuged at 14000 r.p.m to obtain serum. The protein concentration in the samples was determined using the BioRad protein assay kit. Equivalent amounts of protein $(10 \mu \mathrm{g})$ were resolved by electrophoresis on SDSPAGE gels and transferred onto Nitrocellulose membranes. Filters were blocked in 5\% dry milk/ $0.2 \%$ Tween 20/ PBS and Western blot analysis was performed with goat polyclonal antibodies against amylase, Santa-Cruz, 1:2000. After incubating the filters for $1 \mathrm{~h}$ with horseradish peroxidaxe (HRP)conjugated anti-goat antibody, Dako, 1:5000, the filters were washed four times in PBS and the HRP signal revealed using the ECL Western-blotting detection system (Amersham Biosciences).

\section{Biochemical Assays}

Commercially available assays were used for the determination of serum pancreatic amylase (Sigma) and lipase (Genzyme Diagnostics) activities. The serum was obtained as described above.

\section{Reverse Transcriptase-PCR Analysis}

The pancreas from control and $p P d \times 1-C r e / S r f^{F / F}$ mice, taken at embryonic or adult stages were dissected, dissolved in Trizol (Invitrogen) and total RNA was extracted according to the manufacturers instructions. Reverse transcriptase reactions were performed using the Cloned AMV/First-strand Synthesis Kit (Invitrogen). The oligonucleotides used for amplification by PCR were: $\beta$-actin (forward) $5^{\prime}$-CGTGGGCCGCCTAGGCACCA-3' ${ }^{\prime}$, (reverse) $5^{\prime}$-TTGGCCTTAGGGTTCAGGGGGG- ${ }^{\prime}$; 18 18RNA (forward) 5'-GATACCCGTTGAACCCCATT-3', (reverse) 5'-CCATCCAATCGGTAGTAGCG-3'; Chemokine KC (forward) 5'-GCGAATTCACCATGATCCC AGCCACCC-3', (reverse) 5'-GCTCTAGATTACTTGG GGACACCTTTTAG-3'; ICAM-1 (forward) 5'-TCG GAGGATCACAAACGAAGC- ${ }^{\prime}$, (reverse) 5'-AAC ATAAGAGGCTGCCATCACG- ${ }^{\prime}$; IL-1 $\beta$ (forward) $5^{\prime}-$ GTGTGATGTTCCCATTAGACAGC-3', (reverse) $5^{\prime}$ TGAGAGGTGCTGATGTACCAGTT-3'; IL-6 (forward) 5'-GTTCTCTGGGAAATCGTGGA-3', (reverse) $5^{\prime}$-TG TACTCCAGGTAGCTATGG-3'; TNF- $\alpha$ (forward) $5^{\prime}$-TGAACTTCGGGGTGATCGGTC-3', (reverse) 5'AGCCTTGTCCCTTGAAGAGAAC-3'; NCX1 (forward) 
5'-TCCCTACAAAACTATTGAAGGCACA-3' , (reverse) 5'-TTTCTGATACTCCTCGTCATCGATT-3'; SERCA2 (forward) 5'-TCCCTACAAAACTATTGAAGGCACA$3^{\prime}$, (reverse) 5'-TTTCTGATACTCCTCGTCATCGATT3'; CFTR (forward) 5'-ACCCTTGTGGATGGGGGT TATGTGC-3' ${ }^{\prime}$, (reverse) 5'-CATGGGTTCTGGGAATG GACTC-3'.

Typically 25-30 cycles of amplification were performed. Amplification parameters were: $1 \mathrm{~min}$ denaturation step at $94^{\circ} \mathrm{C}, 1 \mathrm{~min}$ annealing step at $57^{\circ} \mathrm{C}$ and $1 \mathrm{~min}$ elongation step at $72^{\circ} \mathrm{C}$. The products of amplification were run in $2 \%$ agarose gels in the presence of ethidium bromide and either photographed under UV light, or analyzed by Southern-blot using appropriate $\left[{ }^{32} \mathrm{P}\right]$-labelled probes. The bands were quantified by densitometry, and normalized using the 18S RNA as internal control.

\section{Statistical Analysis}

The data are presented as mean \pm s.d. The statistical significance was determined by using a Student's $t$-test. Differences were considered statistically significant at $P$-values $<0.05$.

\section{Results}

The Srf Gene is Expressed in the Developing and Adult Pancreas

We could detect Srf gene expression in the developing pancreas as early as E11 by RT-PCR. Significant amounts of Srf transcripts were detected throughout pancreatic development as well as in the newborn and adult pancreas (Figure 1a). Srf transcripts were also detected in isolated islets of Langerhans and $\beta$-cell lines. Immunohistochemical analysis confirmed the presence of SRF protein in all the epithelial cells of the developing and adult pancreas (Figure 1b, c, $d$ and e). In the mature pancreas SRF was detected in all the three pancreatic cell types: ducts, acini, and endocrine cells. Thus, the pattern of SRF distribution suggested a possible role of this transcription factor in the development or function of the pancreatic cells. The level of SRF detected in the endocrine cells appeared to be higher than in the other cell types (Figure 1d and e). This observation suggested that SRF could be of particular importance for the endocrine cells.

\section{Conditional Inactivation of Srf in the Pancreas}

To determine the possible roles of SRF in the pancreas, we generated mice with pancreas-specific disruption of the Srf gene. These mice were obtained by crossing two transgenic lines. The first transgenic line, carrying floxed $S r f$ alleles $\left(S r f^{\prime} F / F\right)$ has been already described. ${ }^{9}$ Briefly, the exon2 of $\operatorname{Srf}$ and
PGK-Neo cassete have been flanked by LoxP sites to allow their excision following Cre delivery (Figure 2a). This exon encodes the MADS box of SRF. The excision of exon 2 maintains the reading frame between exons 1 and 3, therefore an SRF protein truncated in the MADS box domain is synthesized from the excised Srf allele. It was shown that this protein is unable to bind the DNA and has no negative transdominant effect. ${ }^{9}$ The second line was the $p P d x 1-C r e$ which expresses the recombinase Cre under the control of the promoter of $P d x 1 .{ }^{17}$ The $P d x 1$ gene expression begins at the onset of pancreas development, (E8.5), in the early progenitor cells giving rise to all, the ductal, acinar, and islet cells of the mature pancreas. In the mature pancreas, $P d x 1$ expression becomes restricted to the $\beta$ and $\delta$ cells. In addition, $P d x 1$ is also expressed in the most posterior part of the stomach, the duodenum and the anterior intestine. ${ }^{18}$ By mating the $S r f^{F / F}$ mice with the $p P d x 1$-Cre mice, we obtained mice double heterozygous for the floxed $S r f$ allele and carrying the $p P d x 1-C r e$ transgene ( $p P d \times 1-C r e / S r f^{\prime F /+}$ mice). By intercrossing these heterozygous animals, we generated the expected proportions of the different genotypes including the $p P d x 1-C r e / S r f^{\prime F / F}$ mice (Figure 2b). The $p P d x 1-C r e / S r f^{\prime F / F}$ mice were viable and fertile. To check pancreas-specific inactivation of the $\operatorname{Srf}$ gene in these animals, the excision of exon 2 was analyzed by PCR. As expected, the excision was total in the pancreas (Figure 2c). In the duodenum and intestine the excision was partial (Figure 2c). This is consistent with the fact that in these tissues $P d x 1$ is expressed only by some cells of the villi and the enteroendocrine cells. No excision was detected in the other tissues tested. In the pancreas, we could detect complete excision of the exon 2 as early as E12. Complete excision of the exon 2 of $\operatorname{Srf}$ was detected also in isolated endocrine islets (Figure 2d). Thus, the $p P d x 1-C r e / S r f^{\prime F / F}$ mice present complete and specific disruption of the $S r f$ gene in the pancreas.

\section{The pPdx1-Cre/Srf ${ }^{\mathrm{F} / \mathrm{F}}$ Mice have Normal Pancreas Development}

To assess the possible effects of the conditional inactivation of Srf on pancreas development, we analyzed the morphology of this organ in the $p P d x 1$ Cre/Srf $f^{\prime F / F}$ mice at birth and at 4 weeks of age. The histological analysis of the pancreatic sections of these transgenic animals did not reveal any appreciable alterations neither in newborn pups, nor after 4 weeks of age (Figure 3a). The insulin immunostaining analysis showed no differences in the number of islets relative to total pancreatic weight, suggesting that the endocrine tissue development was not affected in the pancreas lacking functional SRF (Figure $3 \mathrm{~b}$ ). In addition, the morphormetric analysis showed that the relative area of $\beta$-cells in the pancreas of the $p P d x 1-C r e / S r f^{\prime F / F}$ mice was similar 

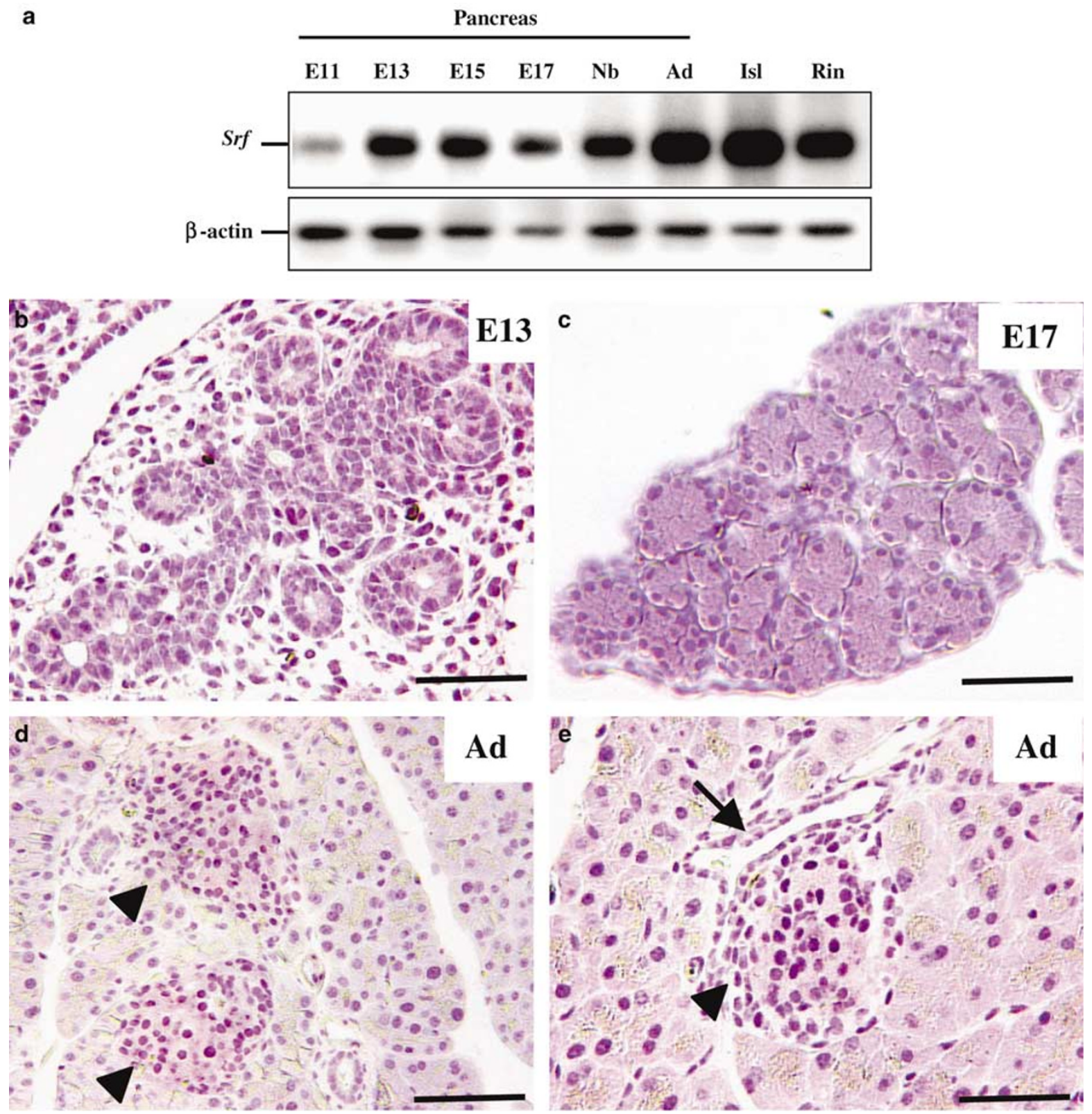

Figure 1 Srf expression in the developing and adult pancreas. (a) RT-PCR analysis showing Srf transcripts at different stages of pancreatic development, as well as in the adult pancreas, isolated islets and the rat pancreatic $\beta$-cell line RIN. (b-e) Immunohistochemical analysis revealing the presence of SRF in the developing and adult pancreatic epithelium. (b, c) SRF is expressed in the undifferentiated epithelium of the E13 and E17 pancreas. (d, e) In the adult pancreas, SRF is detected in all the pancreatic cell types: ductal, acinar, and endocrine cells. Arrows and arrow heads indicate, respectively, ducts and islets. Scale bar in (b), (c) and (d), $100 \mu \mathrm{m}$. Scale bar in (e), $50 \mu \mathrm{m}$. Abbreviations: E (embryonic day), Nb (newborn), Ad (adult), and Isl (islets).

to that of the control animals (Figure 3c). Furthermore, the $\alpha / \beta$-cell ratio also remained unchanged (Figure 3d and e). This indicates that the development of the two major endocrine cell types is normal in these mice. Therefore, SRF is not essential for the fetal or neonatal development of the endocrine cells of the pancreas. Immunostaining for amylase and Dolihcos Biflorus Agglutinin (DBA), specific markers of acinar and ductal cells, respectively, showed that the development and structure of the exocrine pancreas were not altered in mice lacking functional SRF up to 4 weeks of age (not shown).

\section{The pPdx1-Cre/Srf ${ }^{/ F / F}$ Mice have Normal Insulin Production and Secretion}

The recent finding that $\operatorname{Srf}$ is induced in $\beta$-cells in response to glucose stimulation prompted us to analyze $\beta$-cell function in the mice lacking 
functional SRF. ${ }^{11}$ The insulin content in the pancreas of the $p P d \times 1-C r e / S r f^{\prime F / F}$ mice at 4 weeks of age was analyzed by RIA and showed no difference with the controls. Thus, the inactivation of Srf had no effect on insulin production. The determination of glucose and insulin in the sera of fed or fasted animals indicated that the regulation of blood glucose and the secretion of insulin were not affected in these mutants (Figure $4 \mathrm{a}$ and b). We also performed intraperitoneal glucose-tolerance test (IPGTT) to analyze the ability of the 4 weeks-old $p P d \times 1-C r e / S r f^{\prime F / F}$ mice to regulate blood glucose levels upon a glucose challenge. The intraperitoneally injected glucose in the mice lacking SRF in the pancreas was cleared with the same efficiency as in control animals (Figure 4c). These analysis were

a

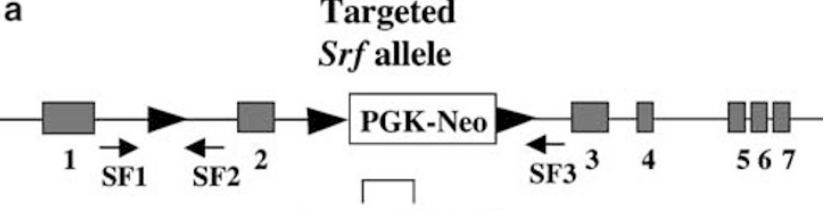

Cre mediated excision

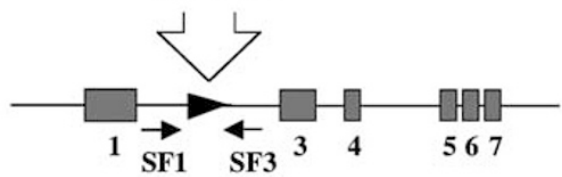

b

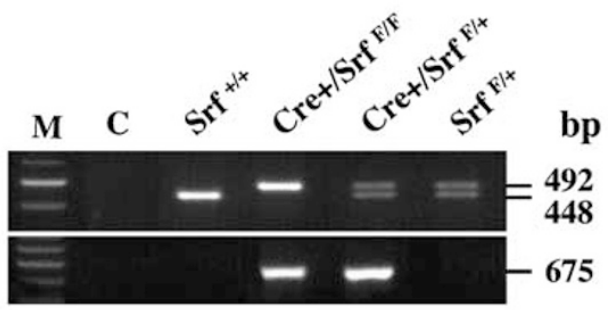

c

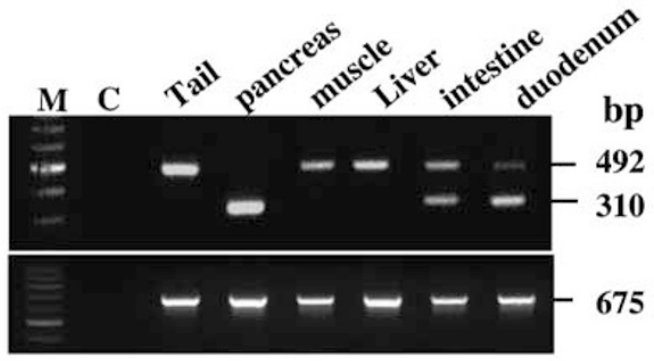

d

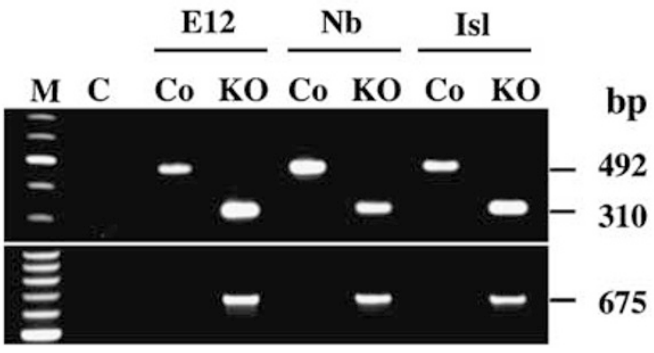

performed also in animals of 2, 3, 5, and 11 months, and we could not detect any alteration in the glucose homeostasis with aging in $p P d \times 1-C r e / S r f^{\prime F / F}$ mice. Therefore, it appears that SRF is not required for normal $\beta$-cell function.

\section{Cell Proliferation is Decreased in the Exocrine Pancreas of the pPdx1-Cre/Srf ${ }^{\mathrm{F} / \mathrm{F}}$ Mice}

As SRF has been implicated in the control of cell proliferation, we analyzed whether the lack of SRF had any effects on the proliferation of the pancreatic cells in the neonatal period. The in vivo proliferation index in the pancreas was analyzed upon injection of BrdU in $p P d x 1-C r e / S r f^{\prime F / F}$ or control mice. Co-staining with anti-BrdU and anti-insulin antibodies allowed us to measure the proliferating index of $\beta$-cells. No significant differences were observed between the mice lacking SRF and the controls (not shown). However, the analysis of acinar cell proliferation revealed that in the $p P d x 1$ $\mathrm{Cre} / \mathrm{Sr} f^{\prime F / F}$ mice the proliferation index of these cells was reduced by twofold as compared to the control animals (Figure 5). Thus, SRF is probably involved in the control of the postnatal proliferative capacity of the pancreatic acinar cells.

\section{Disruption of SRF in the Murine Pancreas Leads to Severe Pancreatitis}

After 6 weeks of age most $p P d \times 1-C r e / S r f^{F / F}$ mice presented mild pancreatic alterations. Among these,

Figure 2 Conditional inactivation of $\operatorname{Srf}$ in the pancreas. (a) Targeting strategy. Structure of the floxed Srf allele and of the disrupted Srf allele upon Cre-mediated excision of exon 2 and of the PGK-Neo cassette. Exons are shown as boxes and arrowheads indicate the position of the LoxP sites. Small arrows indicate the position of the primers used for the PCR. The Homozygous floxed $S r f^{F / F}$ mice were crossed with $p P d x 1$-Cre mice to obtain $p P d x 1$ $\mathrm{Cre} / \mathrm{Srf} f^{F /+}$ mice, which were intercrossed to generate the $P d x 1$ Cre/Srf ${ }^{F / F}$ animals. In the $p P d \times 1$-Cre transgenic line, the $P d x 1$ promoter drives Cre expression in the pancreas, duodenum and intestine. (b) The genotypes of offspring resulting from intercrossing Pdx1-Cre/Srf ${ }^{F /+}$ mice were identified by PCR. Primers SF1 and SF2 allowed the amplification of a $448 \mathrm{bp}$ fragment for the wild-type Srf allele $\left(S r f^{+/+}\right)$and a $492 \mathrm{bp}$ fragment for the homozygous floxed $\operatorname{Srf}\left(S r f^{F / F}\right)$. Both bands were amplified in heterozygous floxed mice $\left(S r f^{F /+}\right)$. The animals were also screened for the Cre transgene using the specific primers CreS and CreR. A fragment of $675 \mathrm{bp}$ was amplified in the mice carrying the transgene. (c) Analysis of exon 2 excision. DNA was extracted from different tissues from the Pdx1-Cre/Srf ${ }^{F / F}$ mice and analyzed by PCR using primers SF1 and SF3. A fragment of $310 \mathrm{bp}$ was amplified upon excision of exon 2 and the PGK-Neo cassete. As expected, the excision is total in the pancreas. Partial excision is also detected in the intestine and duodenum. Excision of exon 2 could not be detected in the tissues (ie muscle, liver, tail) where the $P d x 1$ gene is not expressed. (d) Analysis of exon 2 excision in embryonic, newborn pancreas and isolated endocrine islets. In the pancreas, excision of exon 2 is already total by E12. Isolated islets from 1-month-old $p P d \times 1-C r e / S r f^{F / F}$ mice present complete excision of the exon 2 of Srf. Abbreviations : M (molecular weight marker), C (negative PCR control), Co (control animals, $\operatorname{Sr} f^{F / F}$ ), KO (pPdx1-Cre/Srf $f^{F / F}$ mice). 

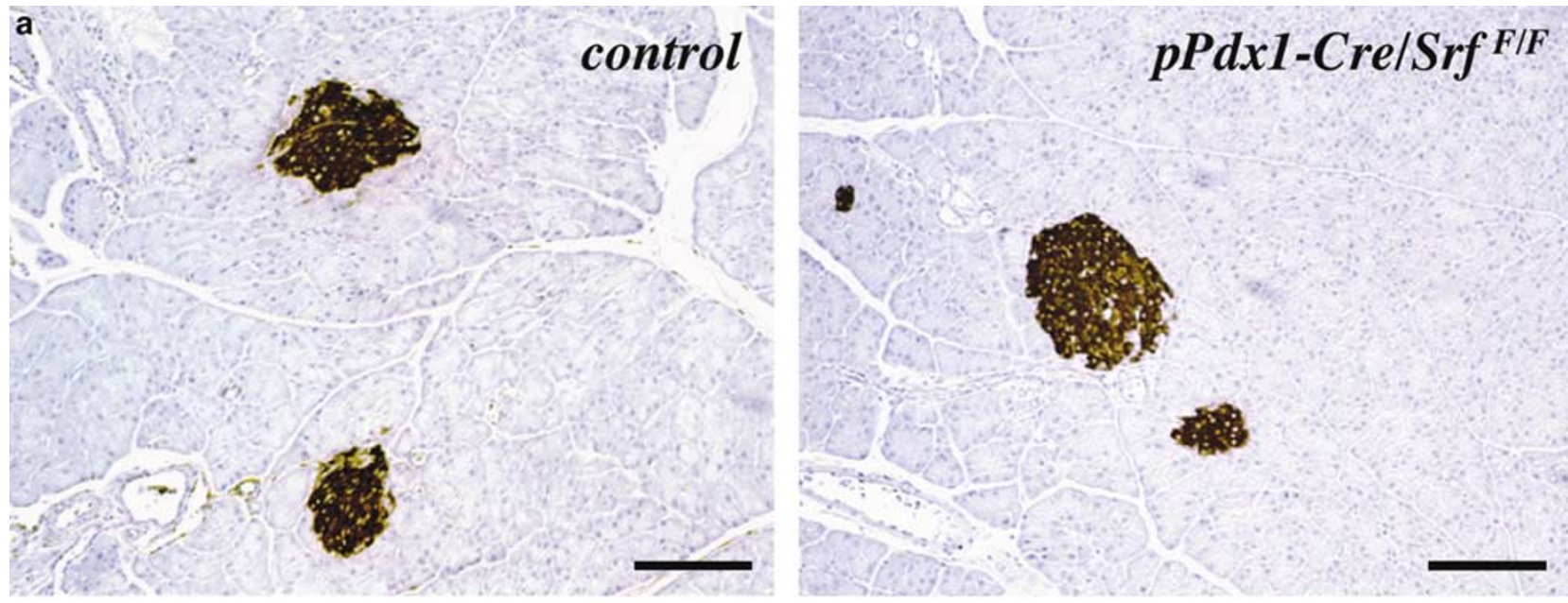

b

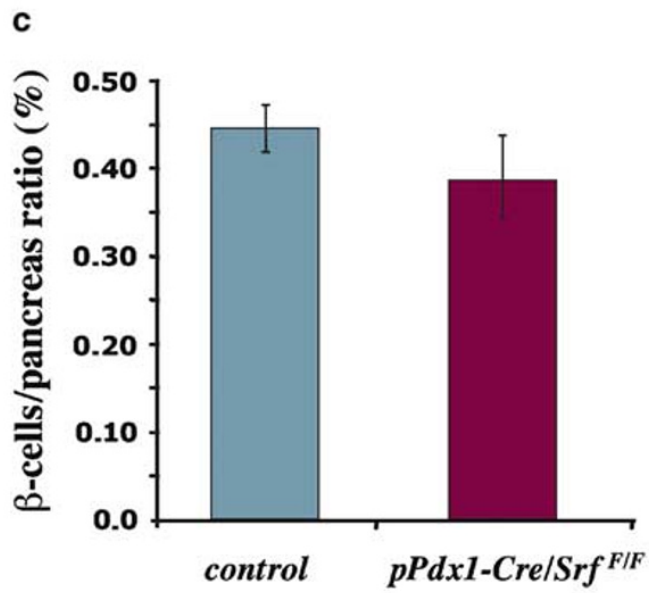

d
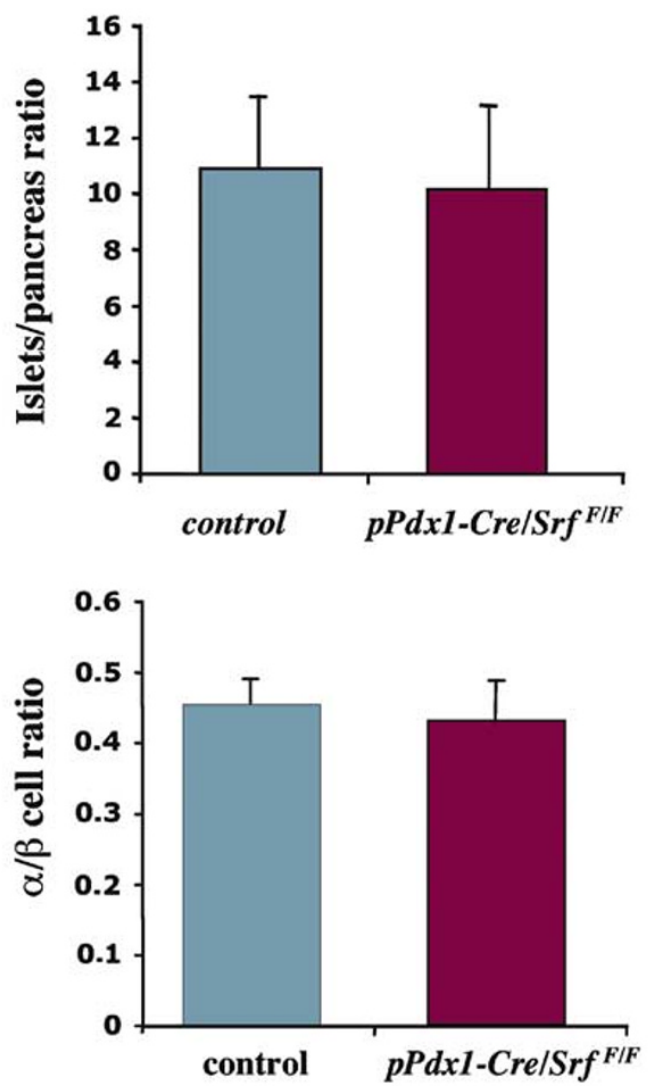

e
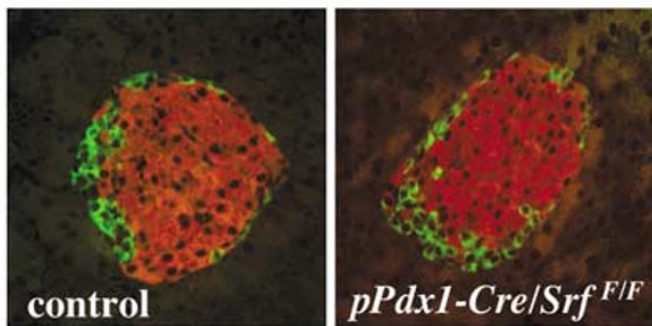

Figure 3 Analysis of the pancreas of 4-week-old $p P d x 1$-Cre/Srf ${ }^{F / F}$ mice. (a) Pancreatic sections of control and $p P d \times 1$-Cre/Srf $f^{F / F}$ mice immunostained for insulin and couterstained with hematoxylin-eosin. In $p P d x 1-C r e / S r f^{F / F}$ mice the overall appearance of the pancreas is similar to that of the control animals. Scale bars, $200 \mu \mathrm{m}$. (b) Relative pancreatic islet numbers. The number of islets was counted in every fifth section of $5 \mu \mathrm{m}$ thickness from a whole pancreas. The numbers were relative to pancreas weight to determine the islet/pancreas ratio. (c) Total $\beta$-cell area calculated as the ratio between the insulin-staining surface relative to the total pancreatic section surface. Although the $\beta$-cells area appears sligthly reduced in the $p P d x 1-C r e / S r f^{F / F}$ compared to the controls, this difference is not statistically significant. (d) $\alpha / \beta$ cell ratio. $\alpha$ and $\beta$ cells were counted after insulin and glucagon immunostaining in at least 25 pancreatic sections for each mouse analyzed. (e) Representative micrographs showing insulin (red fluorescence) and glucagon (green fluorescence) immunostaining in control and $p P d x 1-C r e / S r f^{F / F}$ mice. Control animals included $S r f^{F / F}$ and wild-type mice. The data presented are the mean \pm s.d. of at least eight pancreas.

the most representative was the enlargement of the interstitial space within the acinar cells (which could be indicative of edema). At that time a few immune cells could be detected in the interstitial space. Another alteration, although less frequent, was the enlargement of the lumina of some acini (not shown). After 2 months of age important modifications in the overall appearance of the 

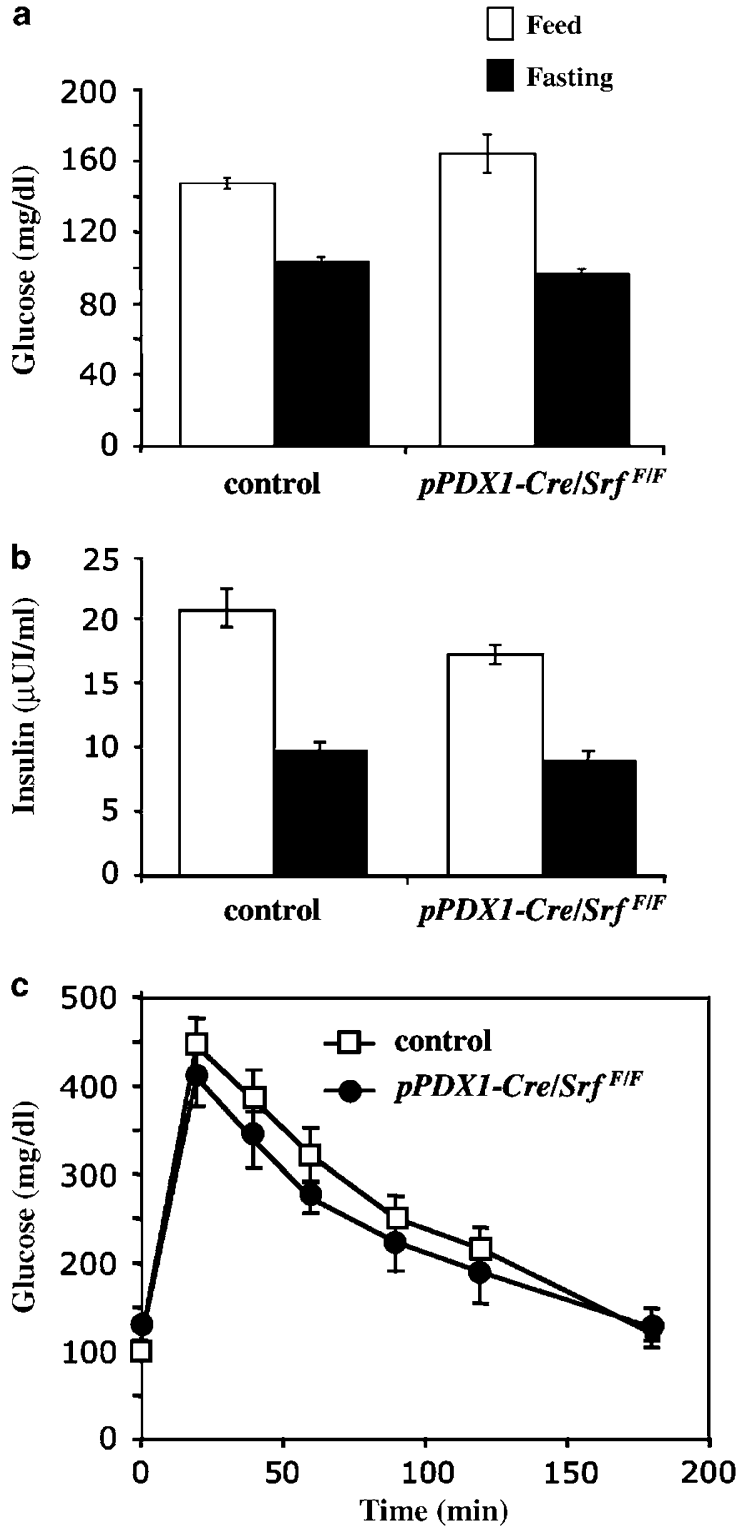

Figure 4 Analysis of the pancreatic endocrine function. (a, b) Plasma levels of glucose (a) and insulin (b) were measured in 4weeks-old control and $p P d \times 1-C r e / S r f^{F / F}$ mice. The measures were done in mice fed ad libitum and after an overnight fast. (c) IPGTT measuring the levels of blood glucose at different times after intraperitoneal injection of glucose in 4-weeks-old control and $p P d x 1-C r e / S r f^{F / F}$ mice. The data are the mean \pm s.d. of at least four animals.

pancreas were detected in the $p P d \times 1-C r e / S r f^{F / F}$ mice. In control animals, the acini are tightly compacted into the pancreatic lobes and, thin septa constituted of connective tissue separate the lobes (Figure 6a and b). In the $p P d \times 1-C r e / S r f^{F / F}$ mice the acini appeared more relaxed, and the trichrome staining revealed abundant collagen deposition and fibrosis within the acini and also within the pancreatic lobes (Figure 6c, d, e and f). Abundant fibrosis was also observed surrounding the islets (Figure 6d). In most sections, the intercalated and
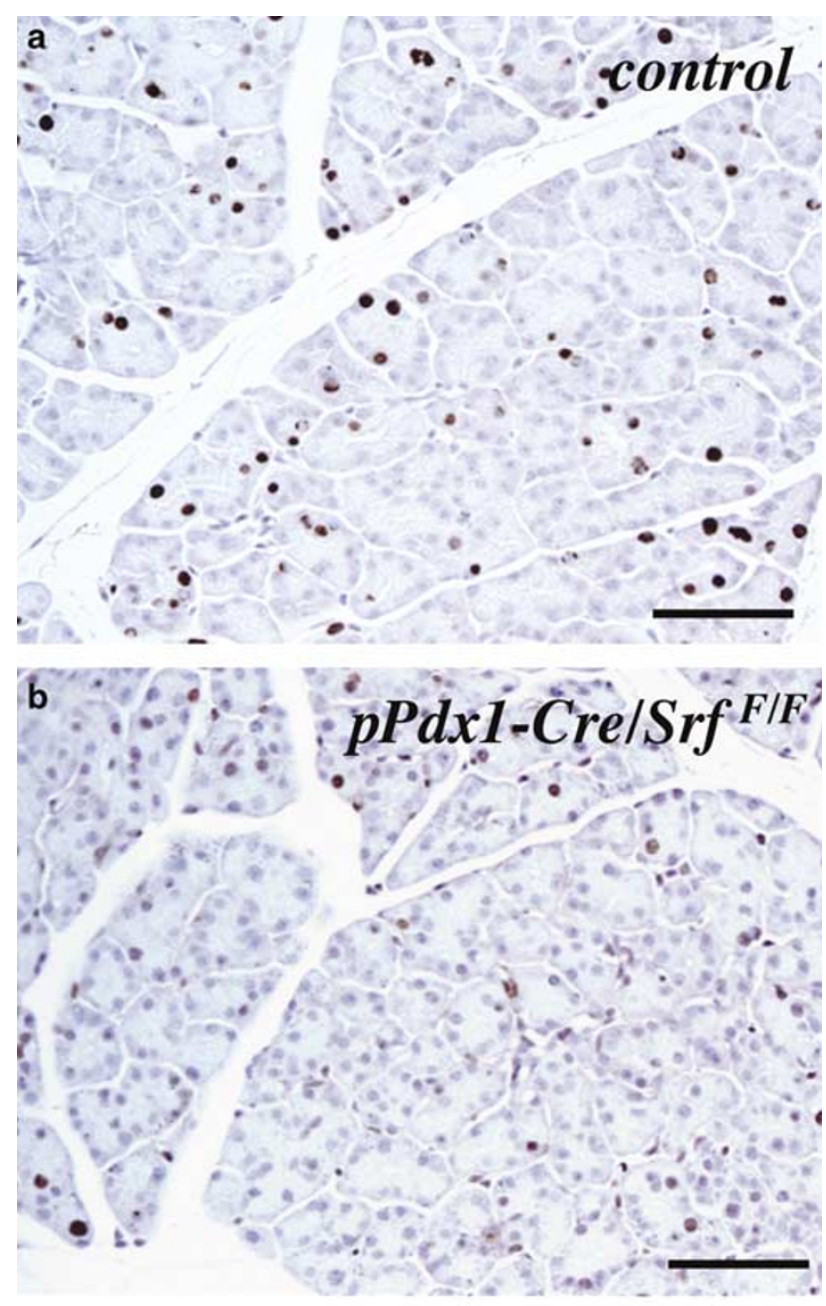

C

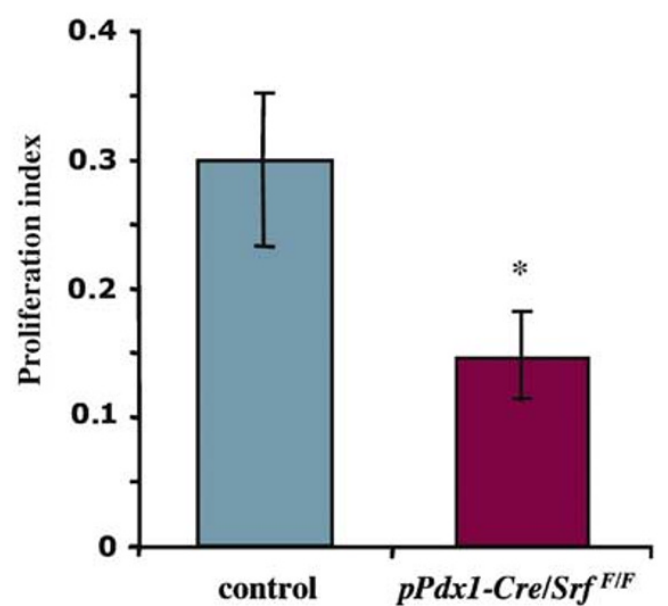

Figure 5 Cell proliferation is decreased in the exocrine pancreas of the $p P d x 1-C r e / S r f^{F / F}$ mice. (a, b) Cell proliferation was determined in 4-weeks-old mice by anti-BrdU immunostaining. The majority of the proliferative cells were acinar cells. Scale bar, $100 \mu \mathrm{m}$. (c) The proliferation index was determined for 25 regions of the control and mutant pancreas. The results are the mean \pm s.d. for four control pancreas and five mutant pancreas. * Statistically significant differences, $P<0.005$. 
intralobular ducts showed significant lumen dilatations (Figure 6e). The hematoxylin-eosin staining of these pancreases revealed an important inflammatory response with abundant inmune cell invasion (Figure 6g, and h). Finally, in some pancreatic lobes the totality of the acinar cells were destroyed and only dilated ducts and a few acinar ghosts persisted (Figure 6h). In older animals (3 months), most pancreatic lobes appeared completely destroyed, and only a few acinar cells could be detected (Figure $7 \mathrm{a})$. At this stage, the intercalated and intralobular ducts, which are usually not apparent, could be easily visualized (Figure 7a and b). The inflammatory response persisted in these animals. At the age of 4 months the exocrine pancreas had completely disappeared in most animals, and was replaced by adipose tissue (Figure 7c and d). No inflammation could be detected at this stage. The islets contained within the adipose tissue appeared qualitatively normal with regard to their morphology, composition and spatial distribution of the different endocrine cell types. The number and size of the islets were also normal. The totality of the animals killed at 11 months of age $(n=7)$ showed an absolute regression of the pancreatic exocrine tissue and its replacement by adipose tissue that surrounded the endocrine islets.

These phenotypic alterations were not observed in $p P d \times 1-C r e / S r f^{F /+}, p P d \times 1-C r e$, and $S r f^{F / F}$ mice.

\section{The pPdx1-Cre/Srf ${ }^{\mathrm{F} / \mathrm{F}}$ Mice Display Pancreatic Enzymes in Serum}

In pancreatitis, the massive destruction of the acinar cells leads to the passage of pancreatic digestive enzymes into the serum. Thus, we performed a Western-blot analysis to test for the presence of pancreatic amylase in the serum of 2 to 3 monthsold control and $p P d \times 1-C r e / S r f^{F / F}$ mice. No pancreatic amylase could be detected in the serum of the control animals while high levels of this enzyme were easily detected in the serum of the $p P d \times 1-C r e /$ $S r f^{F / F}$ mice (Figure 8a). For a more detailed analysis, we measured the enzymatic activities of pancreatic amylase and lipase in the serum (Figure $8 \mathrm{~b}$ and c). This analysis showed that during the first weeks of age only very low amylase or lipase activity can be detected in the serum of the animals, however, in 2 or 3 month-old animals the serum presented high levels of pancreatic amylase and lipase activities. In older animals, the levels of pancreatic amylase and lipase activity in the serum declined rapidly, and by 6 months of age they became almost undetectable. The serum of control animals displayed very low pancreatic amylase or lipase activity at every age analyzed. The immunohistological analysis of the pancreas revealed a good correlation between the degree of pancreatic injury and the amylase and lipase activity in the serum. The rapid decline in pancreatic enzyme activities in the serum of 4- to 5-month-old $p P d x 1-C r e / S r f^{F / F}$ mice appears to be consistent with the fact that at that age most of the exocrine pancreas has been already destroyed.

\section{The 2-Month-Old pPdx1-Cre/Srf ${ }^{\mathrm{F} / \mathrm{F}}$ Mice Show High Levels of Transcripts Encoding Proinflammatory Mediators}

The histological analysis of the pancreas of 2month-old $p P d \times 1-C r e / S r f^{F / F}$ mice showed ongoing local inflammation. It has been suggested that in pancreatitis, the activation of the transcription factor Nuclear factor kappaB (NF- $\kappa \mathrm{B})$ is an early event. ${ }^{20,21}$ Once stimulated, NF- $\kappa \mathrm{B}$ leads to the local production of several proinflammatory cytokines. We analyzed the activation of NF- $\kappa \mathrm{B}$ in the pancreas of the $p P d \times 1-C r e / S r f^{F / F}$ mice by using a monoclonal antibody directed against the p65 subunit of NF- $\kappa$ B. This antibody recognizes an epitope overlapping the nuclear localization signal of the p65 subunit of the $\mathrm{NF}-\kappa \mathrm{B}$ heterodimer. Thus, it selectively binds to the activated form of NF- $\kappa$ B. The immunohistological analysis showed that in the $p P d \times 1-C r e / S r f^{F / F}$ mice many acinar cells were strongly stained with the anti-NF- $\kappa$ B p65 subunit antibody (Figure 9a). In the control animals, we did not detect any stained acinar cells. A semiquantitative RT-PCR analysis was conducted in order to detect the transcripts of several proinflammatory mediators in the pancreas of control and $p P d \times 1-C r e / S r f^{F / F}$ mice (Figure $9 \mathrm{~b}$ and c). In the pancreas of the control animals, very low levels of these transcripts could be detected. On the contrary, the pancreas of the $p P d x 1-C r e / S r f^{F / F}$ mice showed high levels of the transcripts encoding the cytokines TNF- $\alpha$, IL-1 $\beta$ and IL-6, the adhesion molecule ICAM-1 and the chemokine KC.

\footnotetext{
Figure 6 Histological analysis of the pathology in the 2- to 3-month-old $p P d x 1-C r e / S r f^{F / F}$ mice. (a-f) Trichrome staining of pancreatic sections of 2- to 3-month-old control and $p P d x 1$-Cre $/ S r f^{F / F}$ mice. (a) The pancreas of 2-month-old control animals is composed by lobes of tightly associated acinar cells. Ductal cells are not apparent and the endocrine cells are associated forming islets, which are dispersed within the acinar tissue. Thin septa of connective tissue (arrows) separate the pancreatic lobes. (b) Detail of the organization of the endocrine islet cells in the pancreas of control animals. Connective tissue is detected around the blood vessels (arrow) irrigating the endocrine islets. (c-f) The pancreas of 2 months-old $p P d \times 1-C r e / S r f^{F / F}$ mice shows important histological alterations. Abundant fibrosis is observed within the acini and the pancreatic lobes. (d) Fibrosis is also observed surrounding the endocrine islets. (e) The intercalated and intralobular ducts become apparent and show significative dilatations of the lumen. (g, h) The hematoxylin-eosin staining shows that in the mutant mice, the pancreas is largely infiltrated by immune cells indicating that there is an inflammatory response associated with the pathology. (h) Many pancreatic lobes appear to have been almost completely destroyed. In these lobes only a few ghosts of acini and the ducts persist. Scale bar in (a), and (c), $200 \mu \mathrm{m}$. Scale bar in (b), (d), (e), (g) and (h), $100 \mu \mathrm{m}$. Scale bar in (f), $50 \mu \mathrm{m}$.
} 

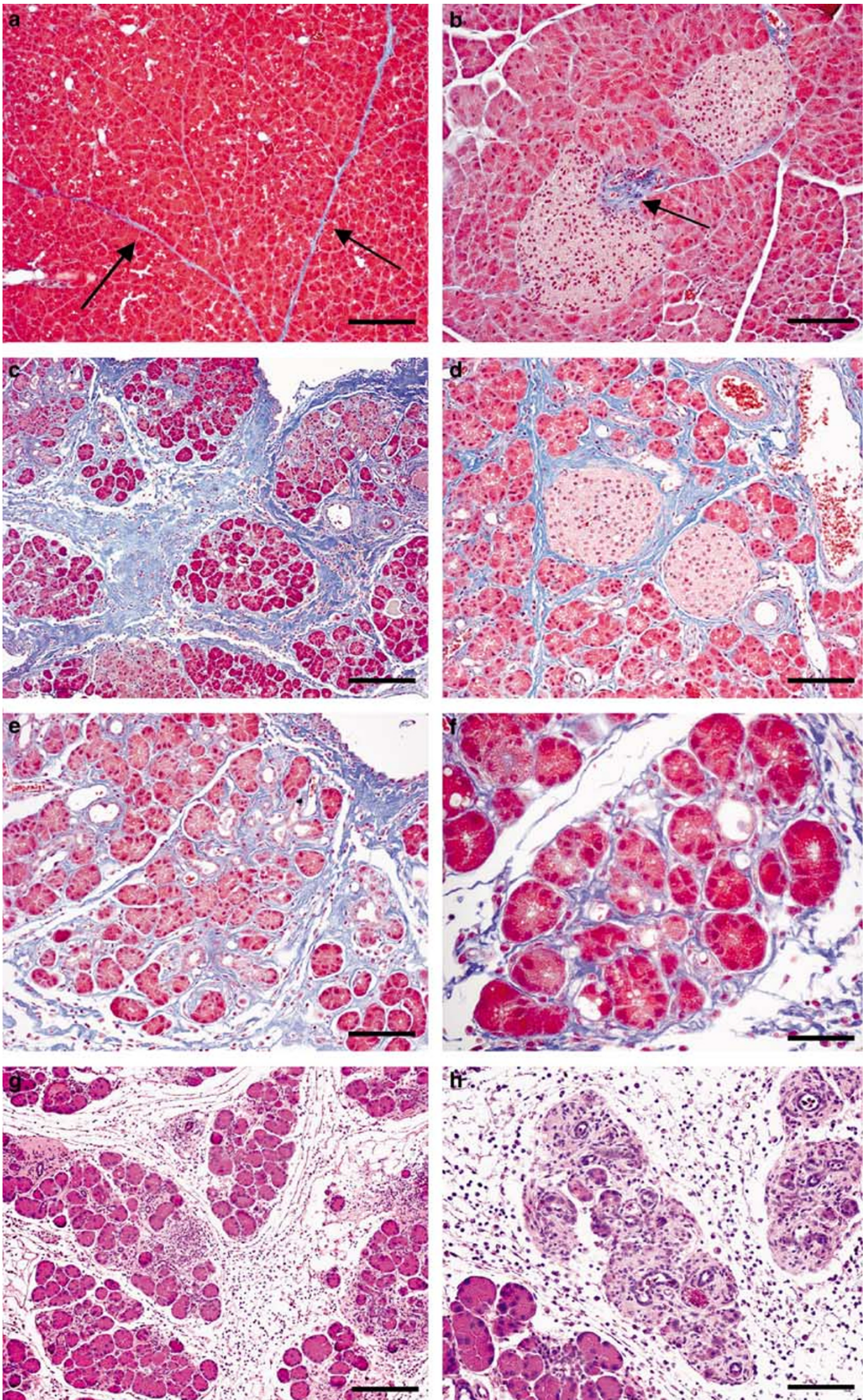


\section{Analysis of Cell Death in the Pancreas of the pPdx1-Cre/Srf ${ }^{\mathrm{F} / \mathrm{F}}$ Mice}

In most models of experimental pancreatitis acinar cell death is believed to result from a combination of apoptosis and necrosis. To determine the contribution of each process in the pancreatitis developed by mice with conditionally disrupted $\operatorname{Srf}$ gene, we examined apoptosis in the pancreas of 2-month-old $p P d \times 1-C r e / S r f^{F / F}$ mice and compared to control animals. The analysis of apoptosis by TUNEL (not shown) and anti-activated caspase- 3 immunostaining (Figure 10) revealed that a few acinar and ductal cells in the $p P d \times 1-C r e / S r f^{F / F}$ mice were apoptotic. In contrast in control animals apoptotic cells were virtually absent. However, the proportion of apoptotic cells in the pancreas of the $p P d \times 1-C r e / S r f^{F / F}$ mice was very low which suggests that apoptosis is not the major cause of cell death in the pancreas of these animals. Therefore, necrosis would be the main cause of acinar cells death in the pancreatitis developed by the $p P d x 1-C r e / S r f^{F / F}$ mice.

\section{Discussion}

SRF is a widely expressed transcription factor, which plays an important role in the control of cell differentiation, proliferation and death. ${ }^{2}$ We have shown in this work that SRF is also expressed in the pancreas. Srf expression starts in the pancreatic epithelium as early as E11 and persists throughout development as well as in the adult. In the mature pancreas, $\operatorname{Srf}$ is expressed in all the three pancreatic cell types: acini, ducts and endocrine cells.

To study the possible role of SRF in pancreas development or function, we have generated and characterized mutant mice with conditional disruption of the Srf gene in the pancreas using the Cre/ LoxP system. This was achieved by crossing mutant
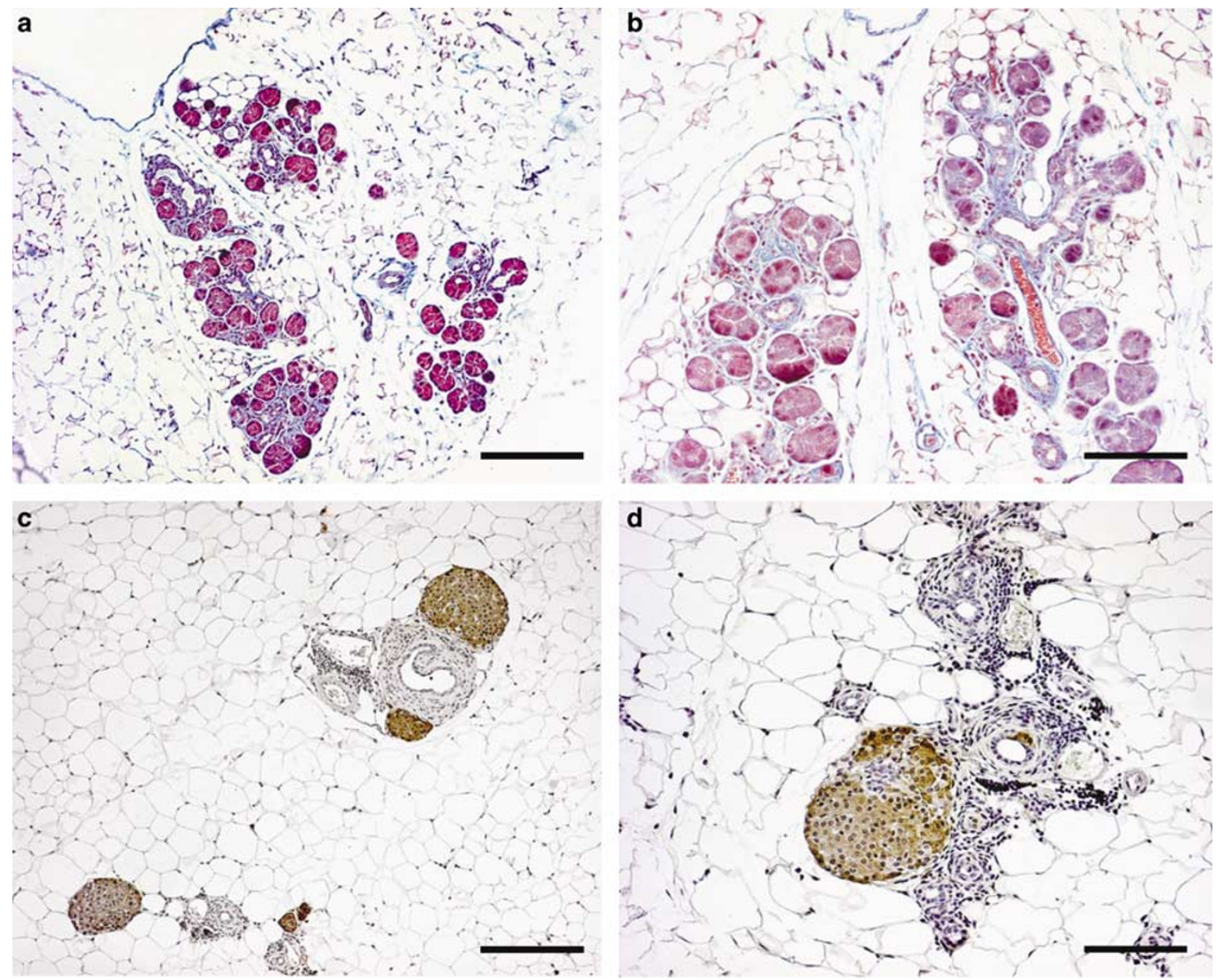

Figure 7 Histological analysis of the pancreas of the 4-month and older $p P d x 1-C r e / S r f^{F / F}$ mice. (a, b) Trichrome staining of pancreatic sections of 4-month-old $p P d x 1-C r e / S r f^{F / F}$ mice. In these animals most of the pancreatic exocrine cells have disappeared. Occasionally a few spots of highly disorganized acinar cells can be observed. These exocrine cells appear surrounded by adipose cells and some fiber deposits. (c, d) Insulin immunostaining and Hematoxyline-eosine staining of pancreatic sections in older animals show that the exocrine cells have completely disappeared while the islets and vascular tissue are surrounded by adipose tissue. (d) Despite the total destruction of the exocrine cells, the islets of the old $p P d x 1-C r e / S r f^{F / F}$ mice present a normal appearance. Scale bar in (a) and (c), $200 \mu \mathrm{m}$. Scale bar in (b) and (d), $100 \mu \mathrm{m}$. 

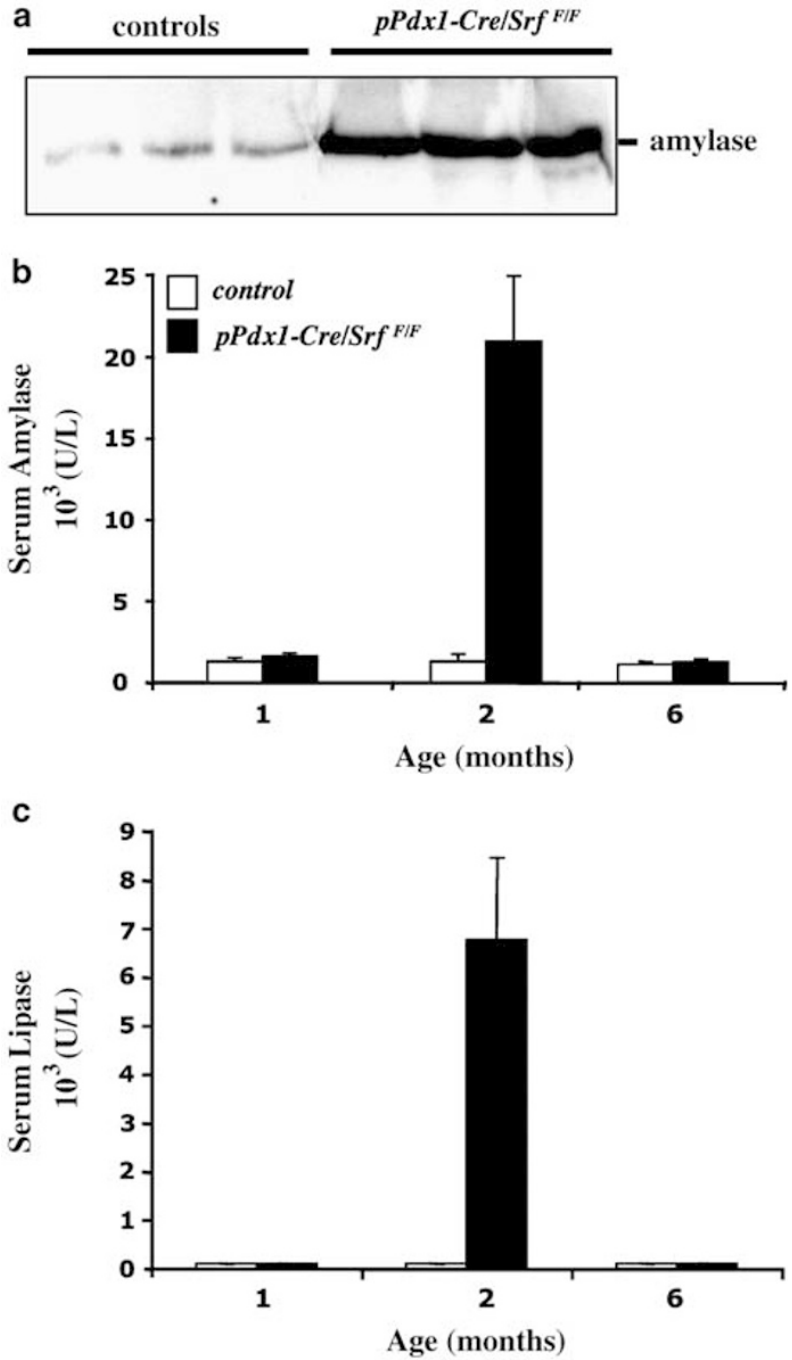

Figure 8 The 2- to 3-month-old $p P d x 1$-Cre/Srf $f^{F / F}$ mice display high levels of pancreatic enzymes in serum. (a) Circulating levels of pancreatic amylase in the 3-month-old control and $p P d \times 1-C r e /$ $S r f^{F / F}$ mice were analyzed by Western-blot. Very low levels of pancreatic amylase are present in the serum of the control animals. However, in the $p P d x 1-C r e / S r f^{F / F}$ mice high levels of circulating pancreatic amylase were detected. (b, c) Pancreatic amylase and lipase activities in the serum of control and $p P d \times 1$ $\mathrm{Cre} / \mathrm{Srf} \mathrm{F}^{F / F}$ mice. These enzymatic activities are almost absent from the serum of the young animals. However, high levels of amylase and lipase activities were detected in the serum of the 2- to 3month-old $p P d x 1-C r e / S r f^{F / F}$ mice. This parallels the onset and development of pancreatitis in these mutant mice. In older animals, the enzyme activities in the serum dropped dramatically likely due to the almost complete destruction of the pancreatic acinar tissue. Columns represent the mean \pm s.d. $(n=4-6)$.

mice carrying a floxed exon 2 allele with $p P d x 1$-Cre mice. The resulting $p P d x 1-C r e / S r f^{F / F}$ mutant mice presented complete Cre-mediated excision of exon 2 , which leads to the production of a nonfunctional SRF protein. These mice were viable and fertile.

The $p P d \times 1-C r e / S r f^{F / F}$ mice presented normal development of both the endocrine and exocrine pancreas indicating that SRF is dispensable for pancreas ontogenesis. A recent study pointed to a possible role of SRF in $\beta$-cell growth and/or function since $\operatorname{Sr} f$ was found to be activated in these cells as a consequence of glucose-induced membrane depolarization. ${ }^{11}$ It was shown that the activation of Srf in $\beta$-cells resulted in the induction of early response genes including Egr-1. These observations suggested that SRF could in particular be implicated in the adaptative response of $\beta$-cells to physiological or pathological situations of increased blood glucose levels. However, we did not detect any alteration in the $\beta$-cell mass or function and the $p P d \times 1$-Cre/Srf $f^{F / F}$ mice were capable of maintaining normal glucose homeostasis. However, we cannot rule out a possible role of SRF on $\beta$-cell mass adaptation and/or insulin production in pathological situations of increased blood glucose levels.

More remarkable and unexpected were the pathological alterations observed after weaning in the exocrine pancreas of the $p P d x 1-C r e / S r f^{F / F}$ mice. These alterations were reminiscent of pancreatitis. Pancreatitis is a local inflammatory process that can lead to the complete destruction of the exocrine pancreas. Intra-acinar activation of digestive enzymes such as cathepsin B and trypsinogen is recognized as the central pathological cause of the disease. The activation of digestive enzymes in the acinar cells is accompanied by the appearance of vacuoles, colocalization of digestive and lysosomal enzymes, activation of NF- $\kappa \mathrm{B}$ and release of proinflammatory cytokines. Although the activated digestive enzymes directly damage the pancreatic parenchyma, the release of cytokines leads to the recruitment of immune cells which infiltrate the pancreas and cause further damage. ${ }^{22,23}$ Morphologically, pancreatitis is characterized by an irregular sclerosis with destruction and loss of the exocrine parenchyma. This is associated with a profound disorganization of the acinar morphology and with varying degrees of dilatation of the intercalated and intralobular ducts. Other morphological alterations include inter and intralobular fibrosis, immune cell infiltration, edema, and focal necrosis. ${ }^{24}$ The histological analysis of the pancreas of the 2-month-old $p P d \times 1-C r e / S r f^{F / F}$ mice revealed profound morphological alterations similar to those described above; namely, acinar disorganization, abundant fibrosis, immune cells infiltration and necrotic pancreatic lobes. Moreover, we could relate these pathological alterations with elevated circulating levels of pancreatic amylase and lipase. The passage of the pancreatic enzymes into the serum is a hallmark of pancreatic pathologies such as pancreatitis. The presence of digestive enzymes in the serum is a consequence of their abnormal pathological release from the basolateral membrane of the acinar cells and subsequent entry into the interstitial and intravascular space. ${ }^{25}$

Another interesting finding was the immunodetection of activated NF- $\kappa \mathrm{B}$ in most acinar cells of the pancreas of the 2-month-old $p P d x 1$-Cre $/ S r f^{F / F}$ mice. In recent years the NF- $\kappa \mathrm{B}$ has gained much attention as one of the principal factors accelerating 

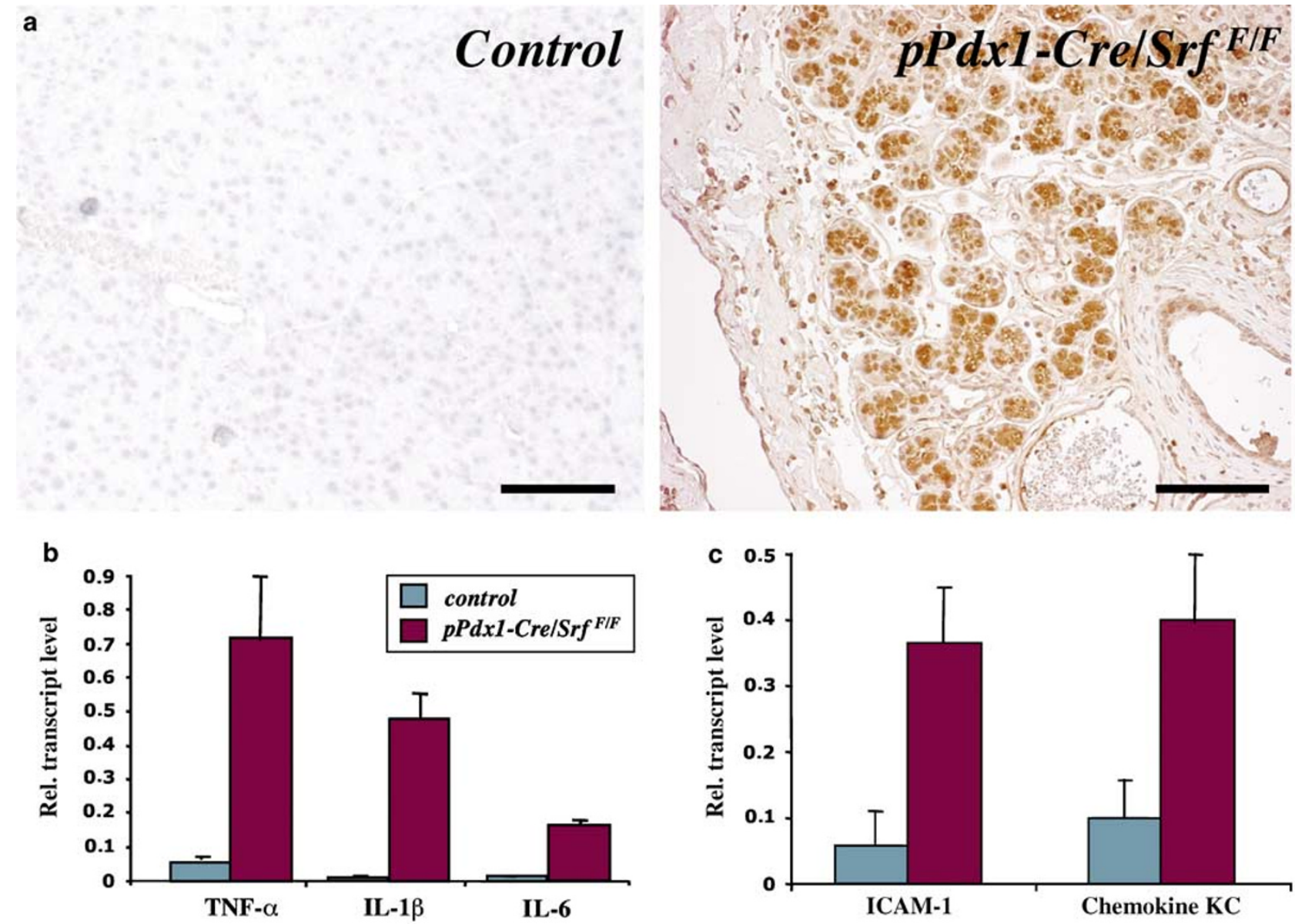

Figure 9 High levels of proinflammatory mediators are expressed in the 2-month-old $p P d x 1$-Cre/Srf $f^{F / F}$ mice. (a) Immunohistological analysis demonstrating the expression of activated NF- $\kappa \mathrm{B}$ in the pancreatic acinar cells of a 2-month-old $p P d x 1-C r e / S r f^{F / F}$ mouse. Scale bar, $200 \mu \mathrm{m}$. (b, c) Semi-quantitative RT-PCR analysis of the transcripts of several proinflammatory mediators. The values were normalized by using the 18S RNA as internal control. The 2-month-old $p P d x 1$-Cre/Srf $f^{F / F}$ mice show high levels of the transcripts encoding the cytokines TNF- $\alpha$, IL-1beta and IL-6 as well as for the adhesion molecule ICAM-1 and the chemokine KC. The bars represent the means \pm s.d. $(n=3)$.

the local inflammatory response in pancreatitis. $\mathrm{NF}-\kappa \mathrm{B}$ is a transcription factor associated with immediate early gene activation, and plays a critical role in the development of necrosis. ${ }^{20,21}$ Although the exact mechanism of $\mathrm{NF}-\kappa \mathrm{B}$ activation in the acinar cells is unknown, once stimulated it leads to the production of several inflammatory cytokines, including TNF- $\alpha$. This cytokine is known to increase the severity of pancreatitis by further increasing cytokine production, enhancing pancreatic leukocyte sequestration and inducing acinar cell apoptosis. ${ }^{26,27}$ The activation of this cascade of proinflammatory mediators was indeed implicated in the pathological alterations observed in the pancreas of the 2- and 3-month-old pPdx1-Cre/ $S r f^{F / F}$ mice. This was evidenced, besides the immunodetection of activated NF- $\kappa \mathrm{B}$, by the increased expression of the mRNAs encoding the proinflammatory cytokines TNF- $\alpha$, IL-1, IL-6, the adhesion molecule ICAM-1 and the chemokine KC. These results, together with the histological detection of abundant immune cell infiltration, indicated that a severe inflammatory process took place in the pancreas of the 2- and 3-month-old pPdx1-Cre/Srf $F^{F / F}$ mice. Despite the strong inflammation observed in the pancreas, the lungs of the $p P d x 1-C r e / S r f^{F / F}$ mice did not present any injury, suggesting that the local inflammation did not evolve into systemic inflammation.

The pancreas of 2- to 3-month-old $p P d \times 1$-Cre/Srf $f^{F / F}$ mice present abundant fibrosis. This was evidenced by strong trichrome staining, and also by immunostaining against different components of the extracellular matrix (ECM), collagen I, fibronectin, and laminin (not shown). Pancreatic fibrosis is a characteristic feature of chronic pancreatitis and pancreatic cancer. Although the mechanism of the fibrotic process in the pathologic pancreas is not fully understood it is believed that damage occurring in the pancreatic parenchyma is associated with cytokine triggered transformation of resident fibroblasts/pancreatic stellate cells (PSCs) into 

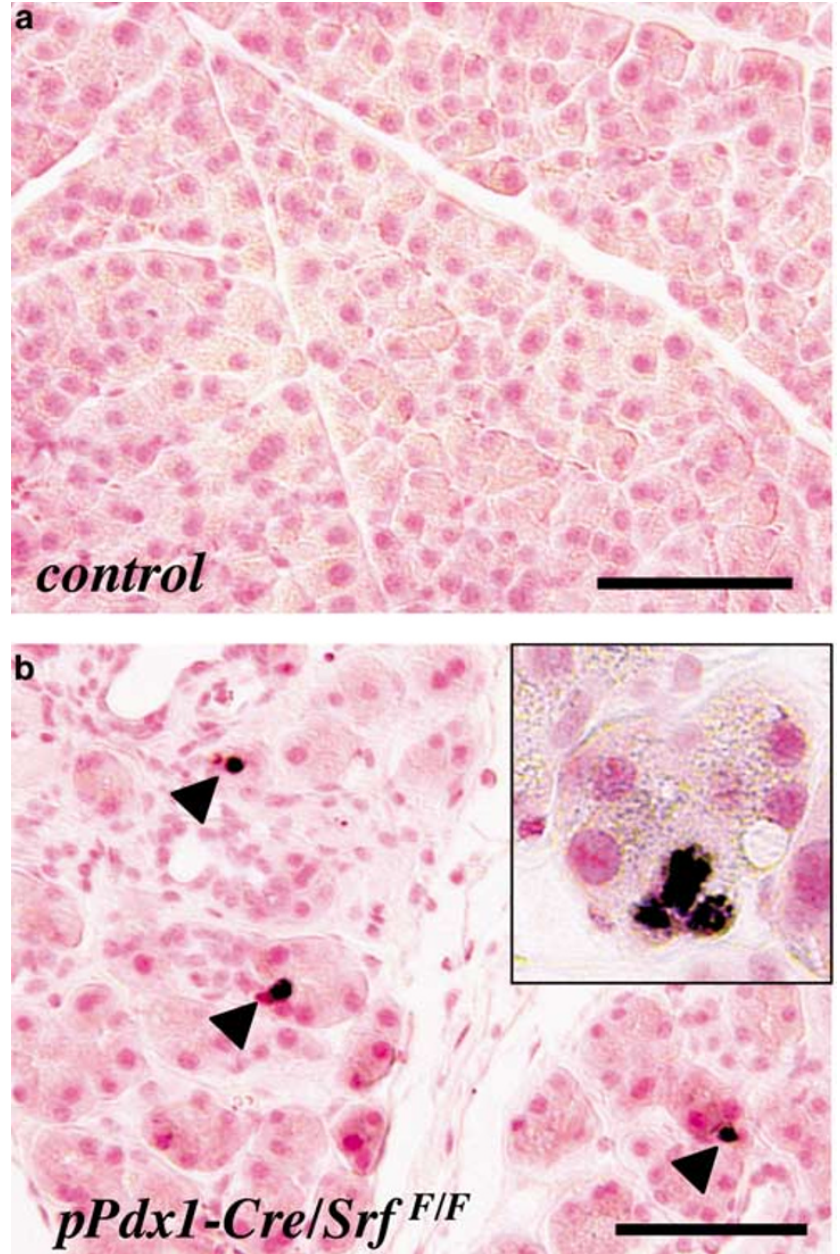

Figure 10 Low levels of apoptosis in the pancreas of 2-month-old $p P d \times 1-C r e / S r f{ }^{F / F}$ mice. (a, b) Representative pictures of antiactivated caspase 3 immunostaining in the pancreas of 2-monthold control and $p P d \times 1-C r e / S r f^{F / F}$ mice. In the pancreas of the control animals, apoptotic cells were absent while only a few apoptotic cells were detected in the pancreas of the $p P d \times 1$-Cre/ $S r f^{F / F}$ mice. As detailed in the inset, the apoptotic cells detected in the mutant pancreas were essentially acinar cells. Scale bars, $100 \mu \mathrm{m}$.

myofibroblasts and the subsequent production and deposition of ECM. ${ }^{28}$ In the 2- to 3-month-old $p P d x 1-C r e / S r f^{F / F}$ mice we have detected high levels of proinflammatory cytokines which could trigger the fibrotic process. Moreover, these mice show also considerable infiltration by immune cells. These cells, in particular the Kupffer cells and macrophages release a number of cytokines such as the platelet-derived growth factor (PDGF) and the transforming growth factor- $\beta$ (TGF- $\beta$ ) which are known to induce fibrosis by activating the PSCs and induce the subsequent production and deposition of ECM. ${ }^{29-31}$ Further studies will determine the implication of the cytokines and PSCs in the fibrotic process developed by the pancreas of the $p P d \times 1$ $\mathrm{Cre} / \mathrm{Sr} f^{F / F}$ mice.

Acinar cell death in pancreatitis is believed to be a combination of apoptosis and necrosis. ${ }^{32,33}$ The
TUNEL and anti-caspase-3 immunohistological analyses showed that the apoptotic index of the exocrine pancreas in the $p P d \times 1-C r e / S r f^{F / F}$ mice was significantly higher than in control animals, However, the relative proportion of apoptotic exocrine cells in the pancreas of these animals remained low. Thus, although present, apoptosis is not likely the prominent cause of acinar cell death in the pancreas of the $p P d \times 1-C r e / S r f^{F / F}$ mice. This provides indirect evidence for necrosis as the major form of acinar cell death in the pancreatitis developed by the $p P d x 1-C r e / S r f^{F / F}$ mice. Our data are consistent with several studies indicating that the degree of apoptosis correlates inversely with the inflammatory response and the severity of pancreatitis. $^{33,34}$ The inflammatory response is generally minor or absent in cell death by apoptosis, which is a highly controlled process; cellular contents are digested, safely packaged in membrane bound bodies and phagocytosed, which spares injury to adjacent cells. ${ }^{33}$ In contrast, necrosis evokes an inflammatory response by leaking intracellular contents from disrupted intracellular membranes. ${ }^{33,34}$

In the $p P d x 1-C r e / S r f^{F / F}$ mice, all these pancreatic injuries led in a relatively short period to the total destruction of the exocrine pancreas. In $p P d \times 1-C r e /$ $S r f^{F / F}$ mice older than 4 months, the exocrine pancreas was completely replaced by adipose tissue that surrounded the vascular network and the endocrine islets. Despite the severe injuries and destruction suffered by the pancreas the organization and function of the endocrine cells remained normal. Thus, the 4-month-old $p P d \times 1-C r e / S r f^{F / F}$ mice and older showed perfect glucose homeostasis. This outcome is similar to what can be observed in some cases of human chronic pancreatitis where islet function remains relatively well preserved. ${ }^{35}$

Pancreatitis has many possible causes. In humans the main etiologic causes of pancreatitis are gallstones and heavy alcohol consumption. However, other causes have been identified including several gene mutations. Among these, the most frequent mutations concern the cationic trypsinogen gene, ${ }^{36}$ the serine protease inhibitor Kazal type 1 gene, ${ }^{37}$ and the CFTR gene. ${ }^{38}$ Irrespective of the etiologic cause, the intra-acinar activation of digestive enzymes is admitted to be the common and key pathological initiator of the injury. The exact mechanism responsible for enzyme activation remains unknown. However, it is now largely admitted that all these changes are triggered by an abnormal, and sustained raise in cytosolic calcium concentration $\left(\left[\mathrm{Ca}^{2+}\right]_{\mathrm{c}}\right)$, which is itself dependent both on release of calcium from endoplasmic reticulum (ER) stores and uptake from the extracellular milieu. ${ }^{39-41}$ Interestingly SRF has been implicated in the transcriptional control of several genes encoding $\mathrm{Ca}^{2+}$ pumps. ${ }^{2,42,43}$ Of these, the Serca2b and NcX1 genes are known to be expressed in the pancreas. ${ }^{14,16}$ The Serca2b gene encodes a $\mathrm{Ca}^{2+}$-ATPase pump which transports $\mathrm{Ca}^{2+}$ from the cytosol to the lumen of the ER. ${ }^{44}$ 
It has been shown that the pharmacological inhibition of SERCA2b results in a sustained raise in $\left[\mathrm{Ca}^{2+}\right]_{\mathrm{c}}$ which leads to the intra-acinar activation of trypsin. ${ }^{45}$ Moreover bile salts have been shown to inhibit the SERCA2b pump and induce a subsequent raise in $\left[\mathrm{Ca}^{2+}\right]_{\mathrm{c}}$. Since bile salt reflux into the pancreas is a common cause of pancreatitis, the inhibition of the SERCA2b pump could be crucial in the initiation of the disease. ${ }^{45,46}$ The Ncx1 gene encodes a $\mathrm{Na}^{+} / \mathrm{Ca}^{2+}$ exchanger pump. ${ }^{47}$ In the pancreas, NCX1 is expressed in the cytoplasmic membranes of acini and ducts. Moreover, the activity of NCX1 is regulated by the pancreatic secretagogues secretin, acetylcholine, and insulin. ${ }^{14}$ Thus, it has been suggested that NCX1 might play an important role in the tight regulation of $\mathrm{Ca}^{2+}$ in the pancreatic juice. Increased concentrations of $\mathrm{Ca}^{2+}$ in the pancreatic juice could result in both $\mathrm{Ca}^{2+}$ stone formation and/or trypsinogen activation, two processes which can led to pancreatitis. ${ }^{48}$

Another gene that has been associated with pancreatitis is the CFTR gene. This gene encodes a transport protein which functions as a chloride channel. In the pancreas, CFTR is predominantly expressed in centroacinar and intralobular duct cells. It was shown that in $\mathrm{Cftr}^{-/}$mice the $\mathrm{Cl}^{-} /$ $\mathrm{HCO}_{3}$ exchange through the pancreatic ducts was perturbed and this resulted in a lack of fluid secretion and premature activation of digestive enzymes. ${ }^{49}$ Although in young animals there was no overt pancreatitis, severe acinar lesions and foci of inflammatory cells become apparent with aging. Moreover, a baseline proinflamatory and antiapoptotic phenotype sensitized these animals to developing more severe pancreatitis with exuberant inflammatory response. ${ }^{34}$ Several CArG boxes have been identified in highly conserved CFTR untranslated regions and a recent study has provided experimental evidence that SRF plays a significant role in CFTR activation. ${ }^{50}$

In view of all these observations, one could have surmised that the eventual downregulation of either Serca2b, Ncx1, or CFTR might explain the development of pancreatitis in the $p P d x 1-C r e / S r f^{F / F}$ mice. However, a semiquantiative RT-PCR analysis did not reveal any differences in the expression of these SRF target genes in the control and $p P d x 1-C r e / S r f^{F / F}$ mice. Further wide analysis of gene expression will be required to search for the SRF target genes, which are involved in the development of pancreatitis in the $p P d x 1-C r e / S r f^{F / F}$ mice.

Genetically engineered animal models of pancreatitis are scarce. Mice with inactivating mutations for the genes encoding the CFTR, ${ }^{51}$ the gap junction protein $\mathrm{C} \times 32,{ }^{52}$ and $\beta$-catenin ${ }^{53}$ develop pancreatic pathologies which are similar to human pancreatitis. We believe that the $p P d \times 1-C r e / S r f^{F / F}$ mice could represent a new model of spontaneous pancreatitis, which could contribute to a better understanding of the physiopathology of this disease.

\section{Acknowledgements}

We are grateful to C Charvet, Dr P Jaffray and D Couton for valuable help and to Dr D Melton for providing the $p P d x 1-C r e$ mice. We are particularly indebt to $\mathrm{M}$ Karaca for helping in islets isolation. We are also indebt to Drs B Terris and F Langa for useful comments. This work was supported by Institut National de la Santé et la Recherche Médicale and the Association Française Contre la Myophatie.

\section{References}

1 Treisman R. Identification and purification of a polypeptide that binds to the c-fos serum response element. EMBO J 1987;6:2711-2717.

2 Chai J, Tarnawski AS. Serum response factor: discovery, biochemistry, biological roles and implications for tissue injury healing. J Physiol Pharmacol 2002;53: 147-157.

3 Shaw PE, Schroter H, Nordheim A. The ability of a ternary complex to form over the serum response element correlates with serum inducibility of the human c-fos promoter. Cell 1989;56:563-572.

4 Hill CS, Wynne J, Treisman R. The Rho family GTPases RhoA, Rac1, and CDC42Hs regulate transcriptional activation by SRF. Cell 1995;81:1159-1170.

5 Schratt G, Philippar U, Hockemeyer D, et al. SRF regulates Bcl-2 expression and promotes cell survival during murine embryonic development. EMBO J 2004; 23:1834-1844.

6 Arsenian S, Weinhold B, Oelgeschlager M, et al. Serum response factor is essential for mesoderm formation during mouse embryogenesis. EMBO J 1998;17: 6289-6299.

7 Zhang X, Chai J, Azhar G, et al. Early postnatal cardiac changes and premature death in transgenic mice overexpressing a mutant form of serum response factor. J Biol Chem 2001;276:40033-40040.

8 Niu Z, Yu W, Zhang SX, et al. Conditional mutagenesis of the murine serum response factor gene blocks cardiogenesis and the transcription of downstream gene targets. J Biol Chem 2005;280:32531-32538.

9 Parlakian A, Tuil D, Hamard G, et al. Targeted inactivation of serum response factor in the developing heart results in myocardial defects and embryonic lethality. Mol Cell Biol 2004;24:5281-5289.

10 Vickers ER, Kasza A, Kurnaz IA, et al. Ternary complex factor-serum response factor complex-regulated gene activity is required for cellular proliferation and inhibition of apoptotic cell death. Mol Cell Biol 2004; 24:10340-10351.

11 Bernal-Mizrachi E, Wice B, Inoue H, et al. Activation of serum response factor in the depolarization induction of Egr-1 transcription in pancreatic islet beta-cells. J Biol Chem 2000;275:25681-25689.

12 Drenckhahn D, Mannherz HG. Distribution of actin and the actin-associated proteins myosin, tropomyosin, alpha-actinin, vinculin, and villin in rat and bovine exocrine glands. Eur J Cell Biol 1983;30: 167-176.

13 Ketola I, Otonkoski T, Pulkkinen MA, et al. Transcription factor GATA-6 is expressed in the endocrine and 
GATA-4 in the exocrine pancreas. Mol Cell Endocrinol 2004;226:51-57.

14 Ankorina-Stark I, Amstrup J, Novak I. Regulation of the $\mathrm{Na}+/ \mathrm{Ca} 2+$ exchanger in rat pancreatic ducts. J Membr Biol 2002;186:43-53.

15 Ahmed N, Corey M, Forstner G, et al. Molecular consequences of cystic fibrosis transmembrane regulator (CFTR) gene mutations in the exocrine pancreas. Gut 2003;52:1159-1164.

16 Dormer RL, Capurro DE, Morris R, et al. Demonstration of two isoforms of the SERCA-2b type $\mathrm{Ca} 2+, \mathrm{Mg}(2+)$ ATPase in pancreatic endoplasmic reticulum. Biochim Biophys Acta 1993;1152:225-230.

$17 \mathrm{Gu} \mathrm{G}$, Dubauskaite J, Melton DA. Direct evidence for the pancreatic lineage: NGN3+ cells are islet progenitors and are distinct from duct progenitors. Development 2002;129:2447-2457.

18 Jonsson J, Ahlgren U, Edlund T, et al. IPF1, a homeodomain protein with a dual function in pancreas development. Int J Dev Biol 1995;39:789-798.

19 Pralong WF, Bartley C, Wollheim CB. Single islet betacell stimulation by nutrients: relationship between pyridine nucleotides, cytosolic $\mathrm{Ca} 2+$ and secretion. EMBO J 1990;9:53-60.

20 Algul H, Tando Y, Schneider G, et al. Acute experimental pancreatitis and NF-kappaB/Rel activation. Pancreatology 2002;2:503-509.

21 Altavilla D, Famulari C, Passaniti M, et al. Attenuated cerulein-induced pancreatitis in nuclear factor-kappaB-deficient mice. Lab Invest 2003;83:1723-1732.

22 Weber CK, Adler G. Acute pancreatitis. Curr Opin Gastroenterol 2003;19:447-450.

23 DiMagno MJ, DiMagno EP. Chronic pancreatitis. Curr Opin Gastroenterol 2003;19:451-457.

24 Steer ML, Saluja AK. Experimental acute pancreatitis: studies of the early events that lead to cell injury. In: Go V, DiMagno E, Gardner J, Lebenthal E, Reber H, Scheele G (eds). The Pancreas: Biology, Pathophysiology, and Disease, 2nd edn. Raven Press Ltd: New York, 1993, pp 489-500.

25 Scheele G, Adler G, Kern H. Exocytosis occurs at the lateral plasma membrane of the pancreatic acinar cell during supramaximal secretagogue stimulation. Gastroenterology 1987;92:345-353.

26 Gukovskaya AS, Gukovsky I, Zaninovic V, et al. Pancreatic acinar cells produce, release, and respond to tumor necrosis factor-alpha. Role in regulating cell death and pancreatitis. J Clin Invest 1997;100: 1853-1862.

27 Norman J. The role of cytokines in the pathogenesis of acute pancreatitis. Am J Surg 1998;175:76-83.

28 DiMagno E, Layer P, JE C. Chronic pancreatitis. In: Go VL DE, Gardner JD, Lebenthal E, Reber HA, Scheele GA (eds). The Pancreas: Biology, Pathophysiology, and Disease. Raven Press Ltd: New York, 1993, pp 665-706.

29 Nagashio Y, Ueno H, Imamura M, et al. Inhibition of transforming growth factor beta decreases pancreatic fibrosis and protects the pancreas against chronic injury in mice. Lab Invest 2004;84:1610-1618.

30 Luttenberger T, Schmid-Kotsas A, Menke A, et al. Platelet-derived growth factors stimulate proliferation and extracellular matrix synthesis of pancreatic stellate cells: implications in pathogenesis of pancreas fibrosis. Lab Invest 2000;80:47-55.

31 Apte MV, Haber PS, Darby SJ, et al. Pancreatic stellate cells are activated by proinflammatory cytokines: implications for pancreatic fibrogenesis. Gut 1999;44: 534-541.

32 Gukovskaya AS, Perkins $\mathrm{P}$, Zaninovic $\mathrm{V}$, et al. Mechanisms of cell death after pancreatic duct obstruction in the opossum and the rat. Gastroenterology 1996;110:875-884.

33 Kaiser AM, Saluja AK, Sengupta A, et al. Relationship between severity, necrosis, and apoptosis in five models of experimental acute pancreatitis. Am J Physiol 1995;269(5 Part 1):C1295-C1304.

34 Dimagno MJ, Lee SH, Hao Y, et al. A proinflammatory, antiapoptotic phenotype underlies the susceptibility to acute pancreatitis in cystic fibrosis transmembrane regulator $(-/-)$ mice. Gastroenterology 2005;129: $665-681$.

35 Sarner M. Pancreatitis: definitions and classifications. In: Go VL DE, Gardner JD, Lebenthal E, Reber HA, Scheele GA (eds). The Pancreas: Biology, Pathophysiology, and Disease, 2nd edn. Raven Press Ltd: New York, 1993, pp 575-580.

36 Whitcomb DC, Gorry MC, Preston RA, et al. Hereditary pancreatitis is caused by a mutation in the cationic trypsinogen gene. Nat Genet 1996;14:141-145.

37 Witt H, Luck W, Hennies HC, et al. Mutations in the gene encoding the serine protease inhibitor, Kazal type 1 are associated with chronic pancreatitis. Nat Genet 2000;25:213-216.

38 Sharer N, Schwarz M, Malone G, et al. Mutations of the cystic fibrosis gene in patients with chronic pancreatitis. N Engl J Med 1998;339:645-652.

39 Kruger B, Albrecht E, Lerch MM. The role of intracellular calcium signaling in premature protease activation and the onset of pancreatitis. Am J Pathol 2000;157:43-50.

40 Mooren F, Hlouschek V, Finkes T, et al. Early changes in pancreatic acinar cell calcium signaling after pancreatic duct obstruction. J Biol Chem 2003;278: 9361-9369.

41 Ward JB, Petersen OH, Jenkins SA, et al. Is an elevated concentration of acinar cytosolic free ionised calcium the trigger for acute pancreatitis? Lancet 1995;346: 1016-1019.

42 Baker DL, Dave V, Reed T, et al. A novel E box/AT-rich element is required for muscle-specific expression of the sarcoplasmic reticulum Ca2+-ATPase (SERCA2) gene. Nucleic Acids Res 1998;26:1092-1098.

43 Cheng G, Hagen TP, Dawson ML, et al. The role of GATA, CArG, E-box, and a novel element in the regulation of cardiac expression of the $\mathrm{Na}+$ Ca2+ exchanger gene. J Biol Chem 1999;274:1281912826.

44 Pozzan T, Rizzuto R, Volpe P, et al. Molecular and cellular physiology of intracellular calcium stores. Physiol Rev 1994;74:595-636.

45 Voronina S, Longbottom R, Sutton R, et al. Bile acids induce calcium signals in mouse pancreatic acinar cells: implications for bile-induced pancreatic pathology. J Physiol 2002;540(Part 1):49-55.

46 Kim JY, Kim KH, Lee JA, et al. Transporter-mediated bile acid uptake causes Ca2+-dependent cell death in rat pancreatic acinar cells. Gastroenterology 2002;122: 1941-1953.

47 Blaustein MP, Lederer WJ. Sodium/calcium exchange: its physiological implications. Physiol Rev 1999;79: 763-854.

48 Mithofer K, Fernandez-del Castillo C, Frick TW, et al. Acute hypercalcemia causes acute pancreatitis and 
ectopic trypsinogen activation in the rat. Gastroenterology 1995;109:239-246.

49 Lee MG, Choi JY, Luo X, et al. Cystic fibrosis transmembrane conductance regulator regulates luminal Cl-/HCO3- exchange in mouse submandibular and pancreatic ducts. J Biol Chem 1999;274:14670-14677.

50 Rene C, Taulan M, Iral F, et al. Binding of serum response factor to cystic fibrosis transmembrane conductance regulator CArG-like elements, as a new potential CFTR transcriptional regulation pathway. Nucleic Acids Res 2005;33:5271-5290.
51 Snouwaert JN, Brigman KK, Latour AM, et al. An animal model for cystic fibrosis made by gene targeting. Science 1992;257:1083-1088.

52 Frossard JL, Rubbia-Brandt L, Wallig MA, et al. Severe acute pancreatitis and reduced acinar cell apoptosis in the exocrine pancreas of mice deficient for the Cx32 gene. Gastroenterology 2003;124:481-493.

53 Dessimoz J, Bonnard C, Huelsken J, et al. Pancreasspecific deletion of beta-catenin reveals Wnt-dependent and Wnt-independent functions during development. Curr Biol 2005;15:1677-1683. 